\title{
Historical review of early researches on mitogenetic radiation: from discovery to cancer diagnostics
}

\author{
Elena V. Naumova ${ }^{1}$, Anna E. Naumova ${ }^{2}$, Dmitry A. Isaev ${ }^{3}$, and llya V. Volodyaev ${ }^{4}$ \\ ${ }^{1}$ Rzhanov Institute of Semiconductor Physics, Russian Academy of Science, Siberian Branch, 13 Lavrentiev av., \\ Novosibirsk 630090, Russia \\ ${ }^{2}$ Saratov State University, 83 Astrakhanskaya Str., Saratov 410012, Russia \\ ${ }^{3}$ All-Russian Research Institute of Irrigation Fish Breeding, Vorovsky township, Noginsky District, Moscow Region \\ 142460, Russia \\ ${ }^{4}$ Biological faculty, M.V. Lomonosov Moscow State University, GSP-1, 1-12 Leninskie Gory, Moscow 119991, Russia \\ *e-mail: naumova@yandex.ru
}

\begin{abstract}
The review is devoted to the experimental studies of mitogenetic radiation (weak UV-chemiluminescence of biological objects) conducted between 1923 and 1948 years. In this period UV-radiation of various biological objects (so called inductors) and its influence on mitotic rate of other biological objects (detectors) were investigated very actively. Very promising results were obtained including the finding of the peptide tumor marker in blood, which was called cancer quencher due to its ability to quench UV-chemiluminescence of blood. Later these researches were interrupted and almost abandoned. The relevance of the scientific problems addressed in these works to this day is stated, the key experiments and the most valuable results obtained between 1923 and 1948 are described in details and subsequent researches are briefly traced up to the present. The prospects of future development are discussed. (C) 2018 Journal of Biomedical Photonics \& Engineering.
\end{abstract}

Keywords: mitogenetic radiation; Gurwitsch radiation; mitogenetic effect; biochemiluminescence; biophotonics; UV-chemiluminescence; distant interaction; ultraweak photon emission; cancer diagnostics; cancer quencher.

Paper \#3308 received 27 Oct 2018; revised manuscript received 15 Dec 2018; accepted for publication 18 Dec 2018; published online 31 Dec 2018. doi: 10.18287/JBPE18.04.040201.

\section{References}

1. A. G. Gurwitsch, "Die Natur des spezifischen Erregers der Zellteilung," Archiv für mikroskopische Anatomie und Entwicklungsmechanik 100(1-2), 11-40 (1923).

2. A. G. Gurwitsch, "Physikalisches über mitogenetische Strahlen," Archiv für mikroskopische Anatomie und Entwicklungsmechanik 103(3-4), 490-498 (1924).

3. O. Rahn, Invisible radiations of organisms, Gebruder Borntraeger, Berlin (1936).

4. A. G. Gurwitsch, L. D. Gurwitsch, Mitogenetic radiation, VIEM publishing house, Leningrad (1934) [in Russian].

5. S. Y. Zalkind, G. M. Frank, Mitogenetic rays and cell division, Gosizdat, Moscow - Leningrad (1930) [in Russian].

6. A. G. Gurwitsch, L. D. Gurwitsch, “Twenty Years of Mitogenetic Radiation: Emergence, Development, and Perspectives," 21st Century Science and Technology 12(3), 41-53 (1999).

7. N. P. N. Database.

8. T. Reiter, D. Gábor, Zellteilung und Strahlung: Sonderheft der Wissenschaftlichen Veröffentlichungen aus dem Siemens-Konzern, Springer-Verlag, Berlin (1928).

9. G. M. Frank, A. G. Gurwitsch, "Zur Frage der Identität mitogenetischer und ultravioletter Strahlen,” Wilhelm Roux' Archiv für Entwicklungsmechanik der Organismen 109(3), 451-454 (1927). 
10. J. Chariton, G. Frank, and N. Kannegiesser, "Über die Wellenlänge und Intensität mitogenetischer Strahlung," Naturwissenschaften 18(19), 411-413 (1930).

11. G. Frank, "Das mitogenetische Reizminimum und -maximum und die Wellenlange mitogenetischer Strahlen," Biol. Zentralbl 49, 129-141 (1929).

12. G. Frank, S. Rodionow, "Über den physikalischen Nachweis mitogenetischer Strahlung und die Intensität der Muskelstrahlung," Die Naturwissenschaften 19(30), 659-659 (1931).

13. G. Frank, S. Rodionow, "Physikalische Untersuchung mitogenetischer Strahlung der Muskeln und einiger Oxydationsmodelle," Biochem Zeitschr 249(4/6), 323-343 (1932).

14. S. Rodionow, G. M. Frank, "On the measurements of mitogenetic radiation by means of a photoelectron register," Archive of Biological Sciences. Ser B. 35(1), 277-288 (1934) [in Russian].

15. L. L. Wassiliew, G. M. Frank, and E. E. Goldenberg, "Versuche über die mitogenetische Strahlung des Nerven," Biol. Zentralbl. 51(5), 225-231 (1931).

16. G. M. Frank, M. Popoff, "Le rayonnement mitogénétique du muscle en contraction," Compte Rendu de l'Academie des Sciences 188, 1010 (1929).

17. G. Frank, M. Kurepina, "Die gegenseitige Beeinflussung der Seeigeleier als mitogenetischer Effekt betrachtet," Wilhelm Roux' Archiv für Entwicklungsmechanik der Organismen 121(4), 634-638 (1930).

18. G. Frank, M. Popoff, "Die mitogenetische Strahlung des Muskels und ihre Verwertung zur Analyse der Muskelkontraktion," Pflüger's Archiv für die gesamte Physiologie des Menschen und der Tiere 223(1), 301 328 (1930).

19. G. Frank, "Über die Erforschung mitogenetischer Strahlung mittels einer neuen nephelometrischen Methode," Biol. Zentralbl. 52(1), 1-12 (1932).

20. A. G. Gurwitsch, L. D. Gurwitsch, “Ultra-Violet Chemi-Luminescence,” Nature 143(3633), 1022-1023 (1939).

21. R. Audubert, "Die Emission von Strahlung bei chemischen Reaktionen," Angewandte Chemie 51(11), 153-163 (1938).

22. A. G. Gurwitsch, L. D. Gurwitsch, An introduction to the teaching of mitogenesis, USSR Academy of Medical Sciences Press, Moscow (1948) [in Russian].

23. A. A. Gurwitsch, The problem of mitogenetic emission as an aspect of molecular biology, «Meditzina», Leningrad (1968) [in Russian].

24. A. G. Gurwitsch, L. D. Gurwitsch, S. Y. Zalkind, and B. S. Pesochensky, The teaching of the cancer quencher: Theory and clinics, USSR Academy of Medical Sciences Press, Moscow (1947).

25. B. S. Pesochensky, The phenomenon of the mitogenetic radiation quenching in blood in cancer and "precancer", Dr. Med. Sci. Dissertation, Leningrad Oncological Institute, Leningrad (1942) [in Russian].

26. B. S. Pesochensky, "Quenching of mitogenetic radiation of blood in cancer and precancerous diseases," Chap. in Collected volume on mitogenesis and theory of biological field, A. G. Gurvitsch (Ed.), Pub.house of the USSR Academy of Medical Sciences, Moscow, 102-114 (1947).

27. E. E. Avchina, On the prognostic value of the reaction of quenching of the mitogenetic radiation of blood in the treatment of uterine cancer, Cand. Med. Sci. Dissertation, Leningrad (1950) [in Russian].

28. I. V. Volodyaev, L. V. Beloussov, "Revisiting the mitogenetic effect of ultra-weak photon emission," Frontiers in Physiology 6(00241), 241 (2015).

29. G. W. Taylor, E. N. Harvey, "The theory of mitogenetic radiation,” Biolog. Bull. 61(3), 280-293 (1931).

30. E. Lorenz, "Search for Mitogenetic Radiation by Means of the Photoelectric Method," J. Gen. Physiol. 17(6), 843-62 (1934).

31. B. Rajewsky, “Anordnung zur Messung kleinster Lichtintensitäten,” Z. Physik 63, 576 (1930).

32. B. Rajewsky, "Zur Frage des physikalischen Nachweises der Gurwitsch-Strahlung," Chap. in Zehn Jahre Forschung auf dem physikalisch-medizinischen Grenzgeibiet, F. Dessauer (Ed.), Georg Thieme Verlag, Leipzig, 244-257 (1931).

33. B. Rajewsky, "Ultraviolett-Strahlung des Eiweiss," Klinische Wochenschrift 10(36), 1672-1673 (1931).

34. W. W. Siebert, H. Seffert, "Physikalischer Nachweis der Gurwitsch-Strahlung mit Hilfe eines Differenzverfahrens," Naturwissenschaften 21(9), 193-194 (1933).

35. H. Barth, "Versuche zum physikalischen Nachweis von mitogenetischer Strahlung," Archive of Biological Sciences. Ser. B. 35(1), 29-35 (1934).

36. O. Glasser, H. Barth, "Studies on the Problem of Mitogenetic Radiation," Radiology 30(1), 62-67 (1938).

37. L. Grebe, A. Krost, and L. Peukert, "Versuche zum physicalischen Nachweis der mitogenetische Strahlung," Strahlentherapie 60, 538-571 (1938).

38. Y. A. Vladimirov, Ultraweak luminescence accompanying biochemical reactions, NASA, C.F.S.T.I., Springfield, Vermont (1966).

39. B. N. Tarusov, I. I. Ivanov, and Y. M. Petrusevich, Ultraweak Luminescence of Biological Systems, Moscow univeristy press, Moscow (1967) [in Russian].

40. Y. A. Vladimirov, E. V. Proskurnina, "Free radicals and cell chemiluminescence," Biochemistry (Moscow) 74(13), 1545-1566 (2009). 
41. V. L. Voeikov, "Reactive oxygen species, water, photons and life," Rivista di biologia 103(2-3), 321-342, (2010).

42. M. Cifra, P. Pospisil, "Ultra-weak photon emission from biological samples: definition, mechanisms, properties, detection and applications," Journal of Photochemistry and Photobiology B: Biology 139, 2-10 (2014).

43. A. A. Gurwitsch, V. F. Eremeev, and Y. A. Karabchievsky, "Ultraweak emission in the visible and ultraviolet regions in oxidation of solutions of glycine by hydrogen peroxide," Nature 206, 20-2 (1965).

44. N. A. Troitskii, S. V. Konev, and M. A. Katibnikov, "Studies on ultraviolet hemiluminescence of biological systems," Biofizika 6, 238-240 (1961).

45. S. V. Konev, I. T. Lyskova, and D. G. Nisenbaum, "Very weak bioluminescence of cells in the ultraviolet region of the spectrum and its biological role," Biofizika 11(2), 361-363 (1966) [in Russian].

46. A. A. Gurwitsch, V. F. Eremeev, and Y. A. Karabchievsky, Energy bases of mitogenetic radiation and its registration on photomultipliers, Meditzina, Moscow (1974) [in Russian].

47. T. I. Quickenden, R. N. Tilbury, "Luminescence spectra of exponential and stationary phase cultures of respiratory deficient Saccharomyces cerevisiae," Journal of Photochemistry and Photobiology B: Biology 8(2), 169-174 (1991).

48. R. N. Tilbury, T. I. Quickenden, "Luminescence from the Yeast Candida utilis and Comparisons across 3 Genera," Journal of Bioluminescence and Chemiluminescence 7(4), John Wiley and Sons, 245-253 (1992).

49. F. A. Popp, Biophotonen. Ein neuer Weg zur Lösung des Krebsproblems. Bd. 6, Verlag für Medizin Dr. Ewald Fischer, Heidelberg (1976).

50. O. Kučera, M. Cifra, "Cell-to-cell signaling through light: just a ghost of chance?" Cell Communication and Signaling 11, 87 (2013).

51. S. N. Mayburov, I. V. Volodyaev, "Photons Production and Communications in Biological Systems," Progress In Electromagnetics Research Symposium Proceedings, Moscow, Russia, 1937-1941 (2009).

52. L. V. Beloussov, A. B. Burlakov, and N. N. Luchinskaya, "Statistical and Frequency-Amplitude Characteristics of Ultraweak Emissions of the Loach Eggs and Embryos under the Normal Conditions and during Their Optic Interactions. 1. Characteristics of Ultraweak Emission in Normal Development and the Optic Role of Egg Envelopes," Russian Journal of Developmental Biology 33(3), 174-181 (2002).

53. L. V. Beloussov, A. B. Burlakov, and N. N. Luchinskaya, "Statistical and Frequency-Amplitude Characteristics of Ultraweak Emissions of the Loach Eggs and Embryos under the Normal Conditions and upon Their Optic Interactions. 2. Changes in Characteristics of Ultraweak Emissions upon Optic Interaction of Groups of Embryos of Different Ages," Russian Journal of Developmental Biology 34(6), 379-388 (2003).

54. L. V. Belousov, F. A. Popp, and N. I. Kazakova, "Ultraweak emissions from chicken eggs and embryos: the nonadditive interaction of 2 emitters and stable nonequilibrium," Ontogenez 28(5), 377-388 (1997) [in Russian].

55. V. F. Eremeev, "Analysis of the mechanism governing mitogenetic radiation of the liver in mice with implanted cancers," Bulletin of Experimental Biology and Medicine 51(4), 486-489 (1961).

56. M. Wainwright, K. Killham, C. Russell, and S. J. Grayston, "Partial evidence for the existence of mitogenetic radiation," Microbiology 143, 1-3 (1997).

57. M. Wainwright, "Historical and recent evidence for the existence of mitogenetic radiation," Perspectives in Biology and Medicine 41(4), 565-571 (1998).

58. M. Wainwright, "Hypothesis - can UV produced by intracellular bacteria cause cancer?" Microbiology 144, 3239-3240 (1998).

59. M. Wainwright, "Forgotten microbiology - back to the future," Microbiology Today 27, 8-9 (2000).

60. A. V. Budagovskij, Distant intercellular interaction, NPLC «Technika», Moscow (2004) [in Russian].

61. A. B. Burlakov, O. V. Burlakova, and V. A. Golichenkov, "Distance interactions of loach embryo in different stage of development," Doklady Akademii nauk 368(4), 562-564 (1999) [in Russian].

62. A. B. Burlakov, O. V. Burlakova, and V. A. Golichenkov, "Distant wave-mediated interactions in early embryonic development of the loach Misgurnus fossilis L.," Russian Journal of Developmental Biology 31(5), 287-292 (2000).

63. Y. A. Nikolaev, "Distant interactions between bacterial cells,” Microbiology 61(6), $751-754$ (1992).

64. M. V. Trushin, "Light-mediated "conversation" among microorganisms," Microbiological Research 159(1), 110 (2004).

65. M. V. Trushin, "Studies on distant regulation of bacterial growth and light emission," Microbiology 149, 363368 (2003).

66. D. Fels, "Cellular Communication through Light," PLoS ONE 4(4), e5086 (2009).

67. L. W. E. Tessaro, B. T. Dotta, and M. A. Persinger, "Bacterial biophotons as non-local information carriers: Species-specific spectral characteristics of a stress response," MicrobiologyOpen 761 (2018).

68. M. V. Trushin, "Distant non-chemical communication in various biological systems," Rivista di biologia 97(4), 399-432 (2004). 
69. F. A. Popp, A. A. Gurwitsch, H. Inaba, J. Slawinski, G. Cilento, K. H. Li, W. P. Mei, M. Galle, R. Neurohr, R. Van Wijk, D. P. J. Schamhart, W. B. Chwirot, and W. Nagl, "Biophoton emission. Multi-author review," Experientia 44(7), 543-600 (1988).

70. M. Cifra, J. Z. Fields, and A. Farhadi, "Electromagnetic cellular interactions," Progress in Biophysics and Molecular Biology 105(3), 223-246 (2011).

71. F. Scholkmann, D. Fels, and M. Cifra, "Non-chemical and non-contact cell-to-cell communication: a short review," American Journal of Translational Research 5(6), 586-593 (2013).

72. R. Van Wijk, "Bio-photons and bio-communication," Journal of Scientific Exploration 15(2), 183-197 (2001).

73. A. G. Gurwitsch, L. D. Gurwitsch, Mitogenetic radiation: physical and chemical bases and applications in biology and medicine, Medgiz, Moscow (1945) [in Russian].

74. S. Y. Zalkind, Mitogenetic rays, USSR Academy of Sciences Press, Moscow, Leningrad (1935) [in Russian].

75. J. B. Tuthill, O. Rahn, "Zum Nachweis mitogenetischer Strahlung durch Hefesprossung," Archiv für Mikrobiologie 4(1-4), 565-573 (1933).

76. A. J. Ferguson, O. Rahn, "Zum Nachweis mitogenetischer Strahlung durch beschleunigtes Wachstum von Bakterien," Archiv für Mikrobiologie 4(1-4), 574-582 (1933).

77. L. K. Wolff, G. Ras, "Einige Untersuchungen über die mitogenetischen Strahlen von Gurwitsch," Zbl. f. Bakteriol. 123, 257-270 (1931).

78. L. K. Wolff, G. Ras, “Ueber mitogenetische Strahlen. IV. Ueber Sekundärstrahlung.," Centralbl. Bakt. Paras, und Infck. Abt. (128), 306 (1933).

79. A. Hollaender, "The problem of mitogenetic rays," Chap. in Biological effects of radiation, B. Duggar (Ed.), McGraw-Hill Book Company, Inc., NY, London, 919-958 (1936).

80. A. G. Gurwitch, Das Problem der Zellteilung physiologisch betrachtet, Julius Springer, Berlin (1926).

81. L. Acs, "Über echte mitogenetische Depressionen. Bakterienantagonismus und mitogenetische Strahlung," Zentralblatt für Bakteriologie, Parasitenkunde und Infektionskrankheiten 6, 342-350 (1933).

82. W. W. Siebert, "Über die mitogenetische Strahlung des Arbeitsmuskels und einiger anderer Gewebe," Biochem. Z. 202, 115-122 (1928).

83. R. Ruyssen, "Sur l'energie et les limites de longueur d'onde des rayons mitogenetiques," Acta Brev. Neerl. 3, 141-142 (1933).

84. A. G. Gurwitsch, L. D. Gurwitsch, "Über ultraviolette Chemolumineszenz der Zellen im Zusammenhang mit dem Problem des Carcinoms.," Biochemische Zeitschrift 196(4-6), 257-275 (1928).

85. M. Kisliak-Statkewitsch, "Die mitogenetische Strahlung des Carcinoms," Zeitschrift für Krebsforschung 29(1), 214-219 (1929).

86. L. Gurwitsch, A. Gurwitsch, "Die mitogenetische Strahlung des Carcinoms," Zeitschrift für Krebsforschung 29(1), 220-233 (1929).

87. A. G. Gurwitsch, Die mitogenetische Strahlung, Julius Springer, Berlin (1932).

88. H. P. Ypsilanti, R. Paltauf, "Zur Frage des Nachweises von Wachstumstrahlen in malignen tierischen Tumoren," Zeitschrift für Krebsforschung 32(1-2), 372-376 (1930).

89. M. Baron, "Analyse der mitogenetischen Induktion und deren Bedeutung in der Biologie der Hefe," Planta 10(1), 28-83 (1930).

90. J. Magrou, M. Magrou, "Radiations emises par le Bacterium tumefaciens,” Rev. Path. Veg. et Ent. Agr. 14, 244-244 (1927).

91. M. J. Magrou, M. M. Magrou, and M. P. Reiss, “Action à distance de divers facteurs sur le developpement de l'oeuf d'Oursin,” Compte Rendu de l'Academie des Sciences 189, 779 (1929).

92. W. W. Siebert, "Über eine neue Beziehung von Muskeltätigkeit und Wachstumsvorgängen," Zeitsch. Klin. Med. 109, 360-370 (1928).

93. L. Acs, "Über die mitogenetische Strahlung der Bakterien," Centr. Bakt. I Abt. Orig. 120(1/2), 116-124 (1931).

94. L. Gurwitsch, A. Anikin, "Das Cornealepithel als Detektor und Sender mitogenetischer Strahlung," Wilhelm Roux' Archiv für Entwicklungsmechanik der Organismen 113(4), 731-739 (1928).

95. L. J. Blacher, N. W. Bromley, "Resorptionsprozesse als Quelle der Formbildung. II. Mitogenetische Ausstrahlungen bei der Regeneration des Kaulquappenschwanzes," Wilhelm Roux' Archiv für Entwicklungsmechanik der Organismen 122(1), 79-87 (1930).

96. L. J. Blacher, N. W. Bromley, "Resorptionsprozesse als Quelle der Formbildung. IV. Mitogenetische Ausstrahlungen bei der Schwanzregeneration der Urodelen," Wilhelm Roux' Archiv für Entwicklungsmechanik der Organismen 123(2), 240-265 (1931).

97. L. J. Blacher, O. G. Holzmann, "Resorptionsprozesse als Quelle der Formbildung. III. Mitogenetische Ausstrahlungen während der Metamorphose bei Urodela," Wilhelm Roux' Archiv für Entwicklungsmechanik der Organismen 123(2), 230-239 (1931). 
98. L. J. Blacher, A. I. Irichimowitsch, L. D. Liosner, and M. A. Woronzowa, "Resorptionsprozesse als Quelle der Formbildung. IX Einfluss der mitogenetischen Strahlen auf die Geschwindigkeit der Regeneration,' Roux' Archiv 127, 339-352 (1932).

99. G. K. Chrustschoff, "Über die Ursachen des Gewebewachstums in vitro. 1. Die Quellen der mitogenetischen Strahlen in Gewebskulturen," Archiv für experimentelle Zellforschung, 9, 203-213 (1930).

100.A. A. Gurwitsch, "L'excitation mitogenetique du systeme nerveux central," Ann. de Physiol. et. Physicochem. Biol. 10, 1153-1153, (1934).

101.L. D. Gurwitsch, S. Salkind, "Das mitogenetische Verhalten des Bluts Carcinomatoser," Biochem. Z. 211, 362-362 (1929).

102.W. W. Siebert, "Die mitogenetische Strahlung des Bluts und des Harns gesunder und kranker Menschen," Biochem. Z. 226(4/6), 253-256 (1930).

103.J. Magrou, “Action a distance et embryogenese,” Radiobiologia 1, 32 (1932).

104.G. Frank, S. Salkind, "Die mitogenetische Strahlung der Seeigeleier," Wilhelm Roux' Archiv für Entwicklungsmechanik der Organismen 110(3), 626-630 (1927).

105.M. A. Baron, "Über mitogenetische Strahlung bei Protisten," Wilhelm Roux' Archiv für Entwicklungsmechanik der Organismen 108(4), 617-633 (1926).

106.H. Guillery, "Uber Bedingungen des Wachstums auf Grund von Untersuchungen an Gowebskulturen," Virchows Archiv 279, 311-311 (1929).

107.G. K. Chrustschoff, "Mitogenetic macroeffect in tissue cultures," Archive of Biological Sciences. Ser B. 35(1), 317-324 (1934) [in Russian].

108.L. K. Wolff, G. Ras, "Effect of Mitogenetic Rays on Eggs of Drosophila melanogaster,” Nature 133(3361), 499-499 (1934).

109.G. Protti, "Il fenomeno della emoradiazione applicato alla clinica," Radiobiologia 1(4), 49-49 (1930).

110.H. Gesenius, "Über die Gurwitsch-Strahlung menschlichen Bluts und ihre Bedeutung für die CarcinomDiagnostik," Biochem. Z. 226, 257 (1930).

111.S. N. Brainess, "Problems of fatigue and activity, and mitogenetic radiation," Archive of Biological Sciences. Ser B. 35(1), 325-340 (1934) [in Russian].

112.V. V. Yefimov, S. P. Letunov, "Influence of work, fatigue, and rest on the blood emission of Gurwitsch's rays," Archive of Biological Sciences. Ser B. 35(1), 157-168 (1934) [in Russian].

113.A. G. Gurwitsch, "Methodik der mitogenetischen Strahlenforschung," Chap in Handbuch der biologischen Arbeitsmethoden, E. Abderhalden (Ed.), 2/2, Urban \& Schwarzenberg, Berlin, Wien, 1401-1470 (1929).

114.V. F. Sarafanow, "On the methods of measuring the growth of yest by means of colorimeters," Archive of Biological Sciences. Ser B. 35(1), 309-316 (1934) [in Russian].

115.K. Nekrasov, D. Laptev, and D. Vetrov, "Automatic detection of cell division intensity in budding yeast," Proceedings of International Conference on Pattern Recognition and Image Analysis (PRIA) 2, 335-339 (2010).

116.A. Hollaender, W. D. Claus, An experimental study of the problem of mitogenetic radiation, National research council of the National academy of sciences, Washington (1937).

117.M. Nakaidzumi, H. Schreiber, "Untersuchungen uber das mitogemrtisehe Strahlungsproblem," Biochem. Z. 237, 358 (1931).

118.K. H. Kreuchen, J. B. Bateman, "Physikalische und biologische Untersuchungen uber mitogenetische Strahlung," Protoplasma 22, 243 (1932).

119.L. K. Wolff, G. Ras, "Über mitogenetische Strahlen. V. Über die Methodik zum Nachweis von Gurwitschstrahlen," Centralbl. Bakt. Paras. und Infck. 128, 314-319 (1933).

120.W. Stempell, "Nachweis der von frischem Zwiebelsohlenbrei ausgesandten Strahlen durch Störung der Liesegangschen Ringbildung," Biol. Zentralbl. 9, 607 (1929).

121.W. W. Siebert, "Das Stempell-Phänomen an den Liesegangschen Ringen,” Biochemishie Zeitschkrift 220(46), 487-492 (1930).

122.W. Stempell, G. V. Romberg, “Über Organismenstrahlung und Organismengasung,” Protoplasma 13(1), 28235 (1931).

123.W. Stempell, Die unsichtbare Strahlung der Lebewesen, Verlag von Gustav Fischer, Jena (1932).

124.W. Stempell, "Das Wasserstoffsuperoxyd als Detektor für Organismenstrahlung und Organismengasung," Protoplasma 12, 538-548 (1931).

125.M. Heinemann, "Physico-chemical test for mitogenetic (Gurwitsch) rays," Nature 134, 701 (1934).

126.M. Heinemann, "Physico-chemical test for mitogenetic (Gurwitsch) rays," Acta Brevia Nederland 5, 15 (1935).

127.W. W. Siebert, H. Seffert, "Zur Frage des Physikalischen Nachweis der Gurwitsch-Strahlung," Archive of Biological Sciences. Ser B. 35, 177-182 (1934).

128.T. I. Quickenden, S. S. Que Hee, "The luminescence of water excited by ambient ionizing radiation," Radiation research 46(1), 28-35 (1971). 
129.T. I. Quickenden, S. S. Que Hee, “The spectral distribution of the luminescence emitted during growth of the yeast Saccharomyces cerevisiae and its relationship to mitogenetic radiation," Photochemistry and Photobiology 23(3), 201-204 (1976).

130.T. I. Quickenden, R. N. Tilbury, "Growth dependent luminescence from cultures of normal and respiratory deficient Saccharomyces cerevisiae," Photochem. Photobiol. 37(3), 337-344 (1983).

131.J. Ponomarewa, "Die mitogenetische Spektralanalyse. III. Mitteilung: Das detaillierte glykolytische Spektrum," Biochem. Z. 239, 424 (1931).

132.G. Decker, “Über die Schärfe mitogenetischer Spektren,” Protoplasma 25(1), 515-527 (1936).

133.S. Y. Zalkind, "Mitogenetic rays and malignant neoplasms," Priroda 6, 53-59 (1938).

134.A. A. Gurwitsch, "Mitogenetic excitation of the central nervous system," Archive of Biological Sciences. Ser B. 35(1), 127-140 (1934) [in Russian].

135.L. D. Gurwitsch, "Mitogenetic spectrum at excitation of proprioceptive nerve filaments," Archive of Biological Sciences. Ser B. 35(1), 141-144 (1934) [in Russian].

136.I. V. Tsoglina, "Mitogenetic physiological spectrum of motor fibers," Archive of Biological Sciences. Ser B. 35(1), 341-342 (1934) [in Russian].

137.N. Kannegiesser, "Die mitogenetische Spektralanalyse. I.,” Biochem. Zeitsch. 236, 415-424 (1931).

138.L. K. Wolff, G. Ras, “Etudes sur le Rayonnement suivant Gurwitsch. VI. Le rayonnement secondaire.," K. Akad. Wetensch. 37(1), 430-445 (1934).

139.H. Gesenius, "Blutstrahlung und Carcinomdiagnostik," Radiobiologia 1(2), 33-36 (1932).

140.W. Siebert, "Die "mitogenetische" Strahlung des Blutes," Chap. in Handbuch der allgemeinen Hämatologie, H. Hirschfeld, A. Hittmair (Eds.), Urban \& Schwarzenberg, Berlin, Wien, 1339 (1934).

141.M. Heinemann, “Cytagenin und „mitogenetische Strahlung” des Blutes,” Klinische Wochenschrift 11(33), 1375-1378 (1932).

142.S. Y. Zalkind, "Mitogenetic rays and some problems of clinical medicine," Priroda 1, 53-59 (1938) [in Russian].

143. Y. S. Klenitsky, "Influence of the surgical tumour removal on the mitogenetic radiation of blood," Archive of Biological Sciences. Ser B. 35(1), 213-218 (1934) [in Russian].

144.M. B. Novikov, "The influence of extirpation of a cancer tumor on the presence of mitogenetic radiation quencher in blood and organs of white mice," Archive of Biological Sciences. 51(3), 56-63 (1938) [in Russian].

145.O. Rahn, "The Disagreement in Mitogenetic Experiments, a Problem in Bacterial Physiology," J. Bacteriol. 28(2), 153-158 (1934).

146.O. Rahn, "The physico-chemical basis of biological radiations," Chap. in Cold Spring Harbor Symposia on Quantitative Biology, Vol. II, Berlin, 226-240 (1934).

147.J. B. Tuthill, O. Rahn, "Analysis of the bud formation of the Baron Method," Archive of Biological Sciences. Ser B. 35(1), 289-296 (1934).

148. O. Rahn, "Mitogenetic radiation," Tabulae biologicae 14, 1-35 (1937).

149.L. Colli, U. Facchini, "Light emission by germinating plants," Il Nuovo Cimento 12(1), 150-153 (1954).

150. Y. A. Vladimirov, F. F. Litvin, "Investigations on ultraweak luminescence in biological systems," Biophysics 4(5), 601-605 (1959) [in Russian].

151.B. N. Tarusov, A. I. Polivoda, and A. I. Zhuravlev, "Detection of chemiluminescence in the liver of irradiated mice," Radiobiologiya 1(1), 150-151 (1961) [in Russian].

152.B. N. Tarusov, A. I. Polivoda, and A. I. Zhuravlev, "Study on ultra-weak spontaneous luminescence of animal cells," Biofizika 6(4), 490-492 (1961) [in Russian].

153.B. N. Tarusov, A. I. Polivoda, A. I. Zhuravlev, and E. N. Sekamova, "Ultraweak spontaneous luminescence in animal tissue," Tsitologiia 4, 696-699 (1962) [in Russian].

154.S. V. Konev, "The nature and biological importance of ultraweak luminescence of a cell," Bioluminescence 21, 181 (1965).

155.A. Boveris, E. Cadenas, and B. Chance, "Ultraweak chemiluminescence: a sensitive assay for oxidative radical reactions," Fed. Proc. 40(2), 195-198 (1981).

156.Y. A. Vladimirov, A. I. Archakov, Lipid peroxidation in biological membranes, Nauka, Moscow (1972) [in Russian].

157.B. N. Tarusov, Ultra-weak luminescence of living organisms, Znanie, Moscow (1972) [in Russian].

158.M. Vacher, I. F. Galvan, B. W. Ding, S. Schramm, R. Berraud-Pache, P. Naumov, N. Ferré, Y.-J. Liu, I. Navizet, D. Roca-Sanjuán, W. J. Baader, and R. Lindh, "Chemi- and Bioluminescence of Cyclic Peroxides," Chemical Reviews 118(15), 6927-6974 (2018).

159.P. Pospisil, A. Prasad, and M. Rac, "Role of reactive oxygen species in ultra-weak photon emission in biological systems," Journal of Photochemistry and Photobiology B: Biology 139, 11-23 (2014).

160.E. P. Sidorik, E. A. Bagley, and M. I. Danko, Cell biochemiluminescence during tumor process, Naukova dumka, Kiev (1989) [in Russian]. 
161.A. I. Zhuravlev, A. I. Zhuharvleva, Ultra-weak luminescence of blood serum and its value in complex diagnostics, Meditzina, Moscow (1975) [in Russian].

162. Y. I. Serkiz, E. E. Chebotarev, V. A. Baraboy, V. E. Orel, and G. E. Chebotarev, Blood chemiluminescence in experimental and clinical oncology, Naukova dumka, Kiev (1984) [in Russian].

163.V. A. Baraboi, V. É. Orel, "Analysis of correlation between kinetics of blood serum chemiluminescence and experimental tumor growth," Bulletin of Experimental Biology and Medicine 107(2), 240-243 (1989).

164.W. S. Metcalf, T. I. Quickenden, "Mitogenetic Radiation,” Nature 216(5111), 169-170 (1967).

165.T. I. Quickenden, S. S. Que Hee, "Weak luminescence from the yeast Saccharomyces cerevisiae and the existence of mitogenetic radiation," Biochem. Biophys. Res. Commun. 60(2), 764-770 (1974).

166.T. I. Quickenden, S. S. Que Hee, "On the Existence of Mitogenetic Radiation," Speculations in Science and Technology 4(5), 453-464 (1981).

167.T. I. Quickenden, M. J. Comarmond, and R. N. Tilbury, "Ultraweak bioluminescence spectra of stationary phase Saccharomyces cerevisiae and Schizosaccharomyces pombe," Photochemistry and Photobiology 41(5), 611-615 (1985).

168.R. N. Tilbury, T. I. Quickenden, "Spectral and Time-Dependence Studies of the Ultraweak Bioluminescence Emitted by the Bacterium Escherichia-Coli," Photochemistry and Photobiology 47(1), 145-150 (1988).

169.R. N. Tilbury, T. I. Quickenden, "The effect of cosmic-ray shielding on the ultraweak bioluminescence emitted by cultures of Escherichia coli," Radiation Research 112(2), 398-402 (1987).

170.T. I. Quickenden, A. J. Matich, S. H. Pung, and R. N. Tilbury, "An attempt to stimulate cell division in Saccharomyces cerevisiae with weak ultraviolet light," Radiation Research 117(1), 145-157 (1989).

171.F. A. Popp, J. J. Chang, A. Herzog, Z. Yan, and Y. Yan, "Evidence of non-classical (squeezed) light in biological systems," Physics Letters A 293(1-2), 98-102 (2002).

172.F. A. Popp, K. H. Li, "Hyperbolic relaxation as a sufficient condition of a fully coherent ergodic field," International Journal of Theoretical Physics 32(9), 1573-1583 (1993).

173.F. A. Popp, B. Ruth, W. Bahr, J. Böhm, P. Graß, G. Grolig, M. Rattemayer, H. G. Shmidt, and P. Wulle, "Emission of visible and ultraviolet radiation by active biological systems," Collective phenomena 3, 187-214 (1981).

174.R. P. Bajpai, "Coherent nature of the radiation emitted in delayed luminescence of leaves," Journal of Theoretical Biology 198(3), 287-299 (1999).

175.I. V. Volodyaev, L. V. Beloussov, "Ultraweak emissions of developing Xenopus laevis eggs and embryos," Russian Journal of Developmental Biology 38(5), 322-328 (2007).

176.I. V. Volodyaev, L. V. Beloussov, "Optical interaction and Ultraweak Luminescence of Embryos of the Frog Xenopus laevis," The 7th International Crimean Conference "Cosmos and Biosphere", Sudak, Crimea, Ukraine, 158-159 (2006).

177.Y. A. Nikolaev, "Distant interaction in the bacterium Pseudomonas fluorescens as a factor of adhesion regulation," Biophotonics and Coherent Systems, Proceedings of the 2nd Alexander Gurwitch conference, F.A. Popp, L. V. Beloussov, V. L. Voeikov, and R. van Wijk (Eds.), Moscow University Press., Moscow, 259266 (2000).

178.C. N. Novikov, N. D. Vilenskaya, E. V. Bouravleva, M. V. Fedorov, and V. L. Voeikov, “Analysis of LowLevel Photon Emission from Non-diluted Human Blood Points to the Regulatory Role of ROS in its Functional Activities," International Symposium "Reactive Oxygen and Nitrogen Species: Diagnostic, Preventive and Therapeutic Values", St. Peterburg-Kizhi-St. Peterburg, 105-106 (2002).

179.C. N. Novikov, N. D. Vilenskaya, Y. Bulargina, and V. L. Voeikov, "Chemiluminescence during respiratory burst in nondiluted human blood can be enhanced by back-reflected photons," Proceedings of SPIE 3569, $17-$ 25 (1998).

180.V. L. Voeikov, Regulatory functions of reactive oxygen species in the blood and in aquatic model systems, D. Biol. Sc. Thesis, Moscow State University, Moscow (2003) [in Russian].

181.M. V. Trushin, "The possible role of electromagnetic fields in bacterial communication," Journal of Microbiology, Immunology and Infection 36(3), 153-160 (2003).

182.V. P. Kaznacheev, L. P. Mikhaylova, Ultraweak radiation in cell interactions, Nauka, Novosibirsk (1981) [in Russian].

183.G. Albrecht-Buehler, "Rudimentary form of cellular "vision"," Proceedings of the National Academy of Sciences 89(17), 8288-8292 (1992).

184.G. Albrecht-Buehler, "Changes of cell behavior by near-infrared signals," Cell Motility and the Cytoskeleton 32(4), 299-304 (1995).

185.A. Farhadi, C. Forsyth, A. Banan, M. Shaikh, P. Engen, J. Z. Fields, and A. Keshavarzian, "Evidence for nonchemical, non-electrical intercellular signaling in intestinal epithelial cells," Bioelectrochemistry 71(2), 142148 (2007).

186.I. V. Volodyaev, Ultra-weak emission and optical interaction in Xenopus eggs and embryos, Ph. D. Thesis, Moscow State University, Moscow (2007) [in Russian]. 
187.G. Reguera, “When microbial conversations get physical,” Trends in Microbiology 19(3), 105-113 (2011).

188.F. A. Popp, "Properties of biophotons and their theoretical implications," Indian Journal of Experimental Biology 41(5), 391-402 (2003).

189.V. L. Voeikov, I. V. Baskakov, K. Kafkalias, and V. I. Naletov, "Initiation of degenerate-branched chain reaction of glycine deamination with ultraweak UV irradiation or hydrogen peroxide," Bioorganicheskaya Khimiya 22(1), 39-47 (1996).

190. V. L. Voeikov, V. I. Naletov, "Weak Photon Emission of Non-Linear Chemical Reactions of Amino Acids and Sugars in Aqueous Solutions," Chap. in Biophotons, J.-J. Chang, J. Fisch and F. A. Popp (Eds.), Springer Netherlands, Dordrecht, 93-108 (1998).

191.A. G. Gurwitsch, L. D. Gurwitch, "Quencher in cancer patients' blood, its value for diagnostic value and antiquencher," Archive of Biological Sciences 51(3), 40-44 (1938) [in Russian].

192.S. Y. Zalkind, "Mitogenetic radiation of blood and diagnosis of malignant neoplasms," Soviet Medical Journal 17, 15-28 (1936) [in Russian].

193.L. I. Sneshko, The role of the spleen in the dynamics of cancer quencher (experimental study), Cand. Med. Sci. dissertation, Dnepropetrovsk State Medical Institute, Dnepropetrovsk (1955) [in Russian].

194.A. G. Gurwitsch, "Physical and chemical bases of mitogenetic radiation," Bulletin of the USSR Academy of Sciences: Physics 9(4-5), 335-340 (1945) [in Russian].

\section{Introduction}

It was almost a hundred years ago, when a distinguished biologist Alexander Gavrilovich Gurwitsch discovered an ability of one biological object (inductor) to influence a mitotic rate of another biological object (detector) by means of very weak UV-radiation $[1,2]$. This phenomenon has been termed the mitogenetic effect, and the UV-radiation, which induced it, was referred to as the mitogenetic radiation.

Experiments of A.G. Gurwitsch attracted great attention of biologists, physicists, and chemists all over the world. First twenty five years after the discovery were the golden age of studies on mitogenetic radiation and mitogenetic effect. In the 1920s-1940s the mitogenetic effect was proved by more than a hundred of researchers in different countries and $>700$ works were published (see reviews of early works [3-6]). A.G. Gurwitsch was awarded with the highest scientific award of the USSR (Stalin Prize, 1941) and received 11 nominations for the Nobel Prize [7] for his works in this area.

Significant contributions were made by famous biologists, physicists, and chemists of that time. Nobel Prize winner D. Gabor with T. Reiter experimentally proved the acting factor of mitogenetic effect to be UVradiation, they studied mitogenetic radiation of various bioobjects, wrote one of the first monographies on the subject [8]. The famous pupil of A.G. Gurwitsch and the founder of Pushchino scientific center, academician G.M. Frank made a number of pioneering experiments in this area: altogether with A.G. Gurwitsch he observed that the weakened UV-radiation from physical sources produces the same mitogenetic effect on biological detectors [9]; he studied the dependence of mitogenetic response of bioobjects from the wavelength and intensity of artificial UV-radiation (with academician Yu.B. Chariton and N.N. Kannegiesser) [10], analyzed spectra of mitogenetic radiation with biological detectors [11], proved an existence of UV-radiation of a number of biological objects and chemical reactions and estimated its intensity with use of modified GeigerMueller counters (with S. Rodionow) [12-14], and made some other important discoveries in this area [5, 15-19]. Nobel Prize winner N.N. Semenov and academician Ya.B. Zeldovich put substantial corrections related to the chain reactions into the Gurwitsch's hypothesis of UV-photons generation [6, 20]. Well-known chemist R. Audubert demonstrated UV-chemiluminescence of a wide range of chemical reactions and biological objects with gas-discharge counters [21]. Academician S.I. Vavilov, who actively participated in scientific discussion on UV-chemiluminescence of bioobjects and chemical reactions [20], claimed the experiments of R. Audubert to be a conclusive evidence of this phenomenon [22]. Significant contributions into the researches of the mitogenetic radiation were made by the All-Union Institute of Experimental Medicine headed by A.G. Gurwitsch, laboratories of L.Ya. Blacher and B.S. Pesochensky (USSR), laboratories of O. Rahn (USA), L.K. Wolff (Netherlands), W.W. Siebert (Germany) and quite a few other reputable research teams and institutions. Many impressive findings were made in both basic and applied researches. For example, UVchemiluminescence of a number of significant biochemical reactions was discovered and studied exactly with help of mitogenetic response of biological detectors, which were more sensitive than physical detectors of that time [23]. Broad study of mitogenetic radiation of blood in various diseases brought up the finding of the "cancer quencher", highly-specific substance appearing in blood in case of any malignant tumor and quenching UV-chemiluminescence [24]. It was shown that the cancer quencher was a peptide or a group of peptides with similar physical and chemical properties. The conclusion that the blood peptide can be used as a tumor marker was made on the basis of experiments on mitogenetic radiation of blood. It was a revolutionary statement for that time. Early cancer diagnostics based on the detection of cancer quencher 
with use of mitogenetic effect was proved in clinical researches (specificity and sensitivity of the method $>95 \%$ ) [25-27].

After twenty five years of successful development of this research area the studies on mitogenetic radiation completely ceased by the late 40s: in Europe they were interrupted at the beginning of the World War II; the "Iron Curtain" strengthened the prejudice against this topic as to obscurantism of "Soviet science"; in the USSR, where this field of research had been developed the most extensively since the beginning, the researches were persecuted altogether with genetics after the decisions of the All-Union Academy of Agricultural Sciences in 1948, see details in [28]. Difficulties in physical detection of ultraweak UV-radiation also contributed to the bias against these researches: photoelectric elements and photographic plates had too low sensitivity to register mitogenetic radiation (for instance, $[29,30])$, and the best modified gas-discharge counters registered it with rather low signal/noise ratio [12, 13, 21, 31-37].

After the complete stoppage of these researches for 8 years, the cell radiation attracted attention of scientists again in the middle 1950s due to the invention of photomultipliers. These studies mainly focused on the visible range, where the chemiluminescence intensity was much higher, see reviews [38-42]. At the same time, experiments with photomultipliers confidently proved an existence of weak UV-chemiluminescence of bioobjects and biochemical processes [43-46] as well as the estimates of its intensity and spectral range made with gas-discharge counters in the 1930s [47, 48]. One more surge in interest to the topic in the 1980-90s was initiated by rather beautiful hypothesis on ability of cells to radiate and highly-selectively detect radiation of extremely high coherence, "biophotons" [49]. This hypothesis has not got enough experimental proof till present $[42,50,51]$, characteristic time of coherence of biological chemiluminescence in optical range seems to be no more than nanoseconds [52-54]. Lots of shallow popular scientific publications about this unverified hypothesis and its mispresentation as an epoch-making discovery in mass media compromised the effect, which this hypothesis was trying to explain.

Although since the middle 1950s the researches somewhat resumed, however, they have been sporadic till now, moreover very few attempts were devoted to verification or progressive development of the scientific heritage of the 1920-40s on mitogenetic effect, for instance, Refs. [23, 46, 55]. Most of contemporary researches on phenomena of optical influence of biological objects on each other, do not attempt to clear whether they relate to UV-radiation, and their results can not be used for verification of old works on mitogenetic effect due to significant difference in experimental conditions [56-67]. Contemporary works are published mainly in English and available for the wide readership. They are clearly described in several reviews [28, 57, 68-72], and here we overview them rather briefly.
The aim of this review is to attract the interest of researchers to the key results of experiments on mitogenetic radiation made between 1923 and 1948 years. During this period a number of research teams headed by outstanding and well-known scientists carried out systematic massive large-scale researches, and, in contrary to the further works they were accompanied by active international discussion and multiple verifications of all the key experiments in different laboratories (see, for example, monographs [4, 5, 8, 24, 73, 74]). Here we review the publications on mitogenetic radiation mostly inaccessible to English readership. They were published in German and in Russian and usually one can not find them neither in libraries nor in the full-text databases, in particular, all the main publications on cancer diagnostics, which are of the most practical interest [24, 25].

Nowadays, researchers, who never have read any original experimental papers on the subject, usually share the common opinion, that the mitogenetic radiation have been proved to be a scientific fallacy of the beginning of the last century, a speculation based on very few occasional experiments. This opinion is as unreasonable as a statement, that all the old experiments on mitogenetic radiation can be trusted without up-todate verification. Moreover, it is difficult to expect that the early attempts to explain these experiments would not require significant revision after almost a century of progress in biology and biochemistry. It also should be taken into account, that in 1923-1948 the experiments methodology (biological methods, statistical treatment of data etc.) was very different from the one used in our day. There were no recent attempts to verify any of these experiments with due attention to details and conditions described in original publications. At the same time, it is significant to mark a number of old experimental works, which were made at the leading edge of research techniques of that time, and their experimental methods and designs seem more convincing now, for instance, Refs. [10, 75-78]. The methods of mitogenetic effect observation were summed up and thoroughly analyzed in Refs. [3, 23], and in Ref. [28], we also recommend the critical review of some methods used in the first decade of experiments [79]. The majority of early works presented in our review were published with detailed protocols and descriptions of methods, and we consider their results worth of serious attention.

Study of scientific heritage of 1923-48 years on mitogenetic radiation, which was accumulated by prominent scientists and their laboratories or institutions, unbiased experimental verification of their results at the up-to-date level of validity are important both for basic science and for practical applications. Study of UV-chemiluminescence of cells is significant not only for better understanding of biochemical processes in them. As it is well known, the biological processes are controlled by complex regulatory systems: both species-specific chemical agents and "quorumsensing factors", highly universal "second messengers", 
as well as relatively recently discovered $\mathrm{NH}_{3}, \mathrm{NO}$ and $\mathrm{CO}_{2}$-mediated regulation. Thorough revision of old experiments opens the door for the enrichment of the theory of regulatory biological processes with a validation of mitogenetic radiation as one more signal agent or with disclosure of another factors, that caused consistent reproduction of the mitotic rate changes in thousands of independent experiments.

The cancer quencher seems the most promising finding for practical applications among the reviewed scientific results. It is surely the first substance suggested as a universal tumor marker [24], about 30 years before the alpha-fetoprotein. It should be noted that the cancer quencher is a blood peptide as well as the most of the tumor markers known by now. It was detected in blood long before any clinical sign of the cancer and was shown to be useful for a differentiation of malignant and non-malignant processes, estimation of efficacy of implemented therapy, timely detection of local recurrences and metastases [24, 25, 27]. Some clinics practiced such a cancer diagnostics at the admission of new patients long before the establishment of the final diagnoses and demonstrated specificity and sensitivity of this method above $95 \%$ [26].

We consider the relevance of problems addressed in researches on mitogenetic radiation and extensive experimental data require verification of these experiments at the up-to-date level, with judging not by public opinion, but by proofs and disproofs, as is customary in science. Confirmation of mitogenetic effect would open wide prospects in biology and medicine; unambiguous refutation would give a novel interpretation to the results of that time. In any case the further progress in this area is impossible without the detailed study of former researches with focus on methods and reproducibility.

\section{The discovery and the first studies of the mitogenetic effect}

The UV-radiation of biological objects was discovered in 1923 by an outstanding Russian biologist Alexander Gavrilovich Gurvitsch [1]. He made a series of experiments with onion (Alium cepa) roots and found that if a tip of one root (inductor) was directed to the meristem of the other root (detector) (Fig. 1), the meristem cells in the detector divided more intensively at the side the inductor root pointed to (Figs. 2, 3).

The phenomenon of distant influence on the mitotic rate was called "mitogenetic effect". Besides the acceleration of the mitotic rate, the deceleration was also observed, but less commonly, for instance, in antagonistic bacteria [81].

The factor that caused the mitogenetic effect exhibited the properties of electromagnetic radiation (straight propagation, reflection, refraction in a quartz prism) $[2,8,82]$. Insertion of plates of materials with different transmittance ranges (mica, glass, gelatin, quartz, wood, etc.) between the inductor and the detector allowed researchers to attribute this radiation to the UV range [1, 8]. The effect was observed when the quartz plate was inserted, but it disappeared with the glass plate. Later, the attribution of the mitogenetic radiation to UV-range was corroborated by the observation of the mitogenetic effect under the influence of weakened UV-radiation from physical sources (spark discharges, mercury lamps) [9, 10, 83] and UV-chemiluminescent reactions [13].

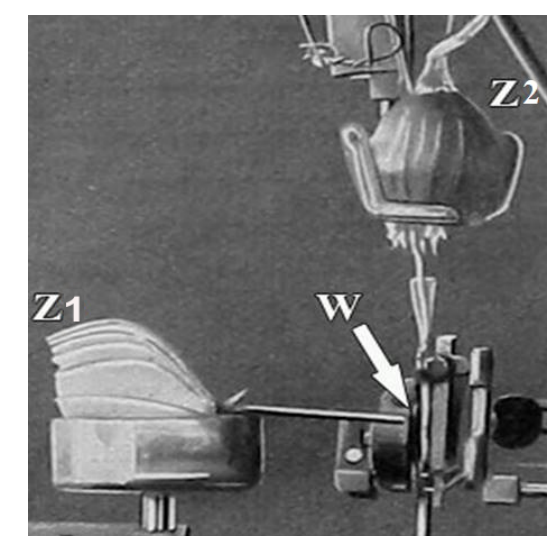

Fig. 1 Gurwitsch's experiment with onion: Z1-inductor onion, $\mathrm{W}$ - the place of mitosis induction, $\mathrm{Z} 2$ - detector onion (reprinted with permission from Ref. [80]).
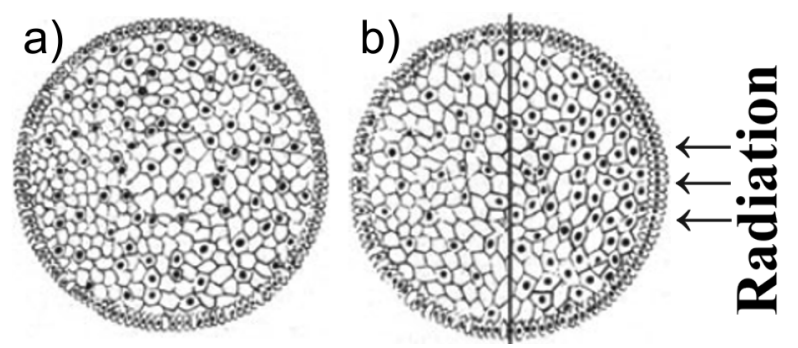

Fig. 2 Schematic drawings of onion meristem crosssections: (a) - non-irradiated root, (b) - irradiated root (reprinted with permission from Ref. [8]).
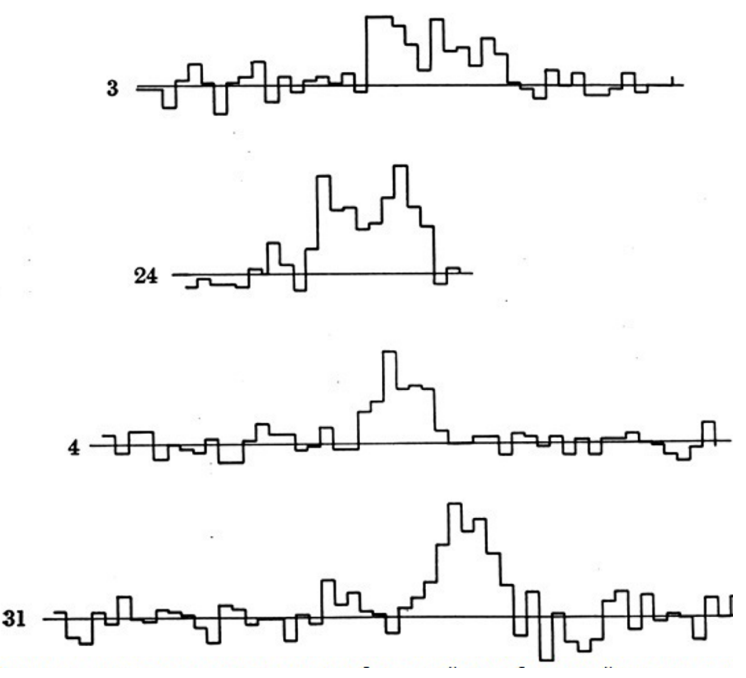

Fig. 3 The difference in the number of mitoses between the irradiated and non-irradiated sides of the root in serial cross-sections (reprinted with permission from Ref. [80]). 
It was found that the phenomenon of mitogenetic effect was not species-specific, for instance, a frog muscle as an inductor and yeast fungi as a detector being representatives of different kingdoms demonstrated a clear mitogenetic effect [11]. Numerous experiments revealed a wide variety of inductors and detectors of mitogenetic effect, it was also found that certain biological objects were not inductors. The absence of species-specificity and the wide variety of inductors and detectors imply that the mechanisms underlying the mitogenetic effect appeared at the early stages of evolution.

The tissues of animals and plants, cell cultures and microorganisms as well as most biological objects under stressful conditions were proved to be sources of mitogenetic radiation.

\section{Inductors}

- Malignant tumors (the most active of the known inductors) [8, 73, 82, 84-88];

- Rapidly proliferating microorganisms [89-93];

- Tissues that A.G. Gurwitsch called "meristems in broad sense", i.e. tissues with mitotically active cells, regardless of the organism taxonomy [8, 87, 94];

- Resorptive and regenerating tissues [95-98];

- Tissue cultures [4, 99];

- Working muscles including the heart [4, 82];

- Excited neurons [100]; 102];

- The blood of young healthy humans $[25,101$,

- Embryos at certain stages (species-specific) [35, 91, 103, 104];

- Most biological objects under stressful conditions [4, 22];

- Physical sources of weak UV-radiation [10, 83];

- Some chemical reactions accompanied by UVluminescence $[3,23]$.

\section{Detectors} 77];

- Bacterial and yeast cultures in lag phase [75-

- "Aging" yeast cultures [89, 105]; probably, they meant cultures not in the stationary phase, but in the so-called "post-diauxic" phase prior to the true stationary G0 phase;

- Tissue cultures [106, 107];

- Plant meristems [1, 8];

- Corneal epithelium (e.g. corneas of tritons, frogs, rats [94]);

- Dividing embryonic cells (sea urchin eggs [90, 91], frog embryos [8], drosophila embryos [77, 108]).

The common features of the detectors were the spontaneous cell division (without any external influences), suboptimal growth conditions [4] (i.e. "ability to be stimulated" relative to the control) and "significant cell complex with adequate proximity of cells" (Ref. [4], p. 332).
Biological objects that are non-inductors of mitogenetic effect

$[3,4]$;

- Non-growing or slowly growing cell cultures

- Internal organs [3];

- Blood of people with various diseases (cancer of different types [25-27, 101, 102], anemia, sepsis, pneumonia, scarlet fever, diabetes, etc. [4, 87, 109, $110])$; blood of elderly or fatigued adults [4, 109, 111, $112]$.

The mitogenetic effect depended on the physiological state of the detector, the inductor and the regime of their interaction. It could manifest itself both in the acceleration of cell cycles, which occurred more often, and in deceleration $[4,81]$.

The mitogenetic response of the detector nonlinearly depended on the distance from the inductor and the exposure duration. There was some optimal range of exposure duration, which resulted in the maximal effect. This range depended on the inductor and detector and on the distance between them; both longer and shorter exposures reduced the effect.

In the first years after the discovery of the mitogenetic effect, the most common detectors were onion roots; the method of detection was described in details and well-established [113]. Later, the onion was replaced with yeast and bacteria detectors, for which it was easier to make a control group; moreover, it was possible to use them as detectors throughout the entire year unlike onion roots, which could be used as detectors only from the end of September to April. In addition, in bacteria and yeast, it was easier to quantify the change in the division rate by physical methods, for example, by measuring the optical density using a nephelometer [19] or a colorimeter [114] (nowadays the budding of yeast is more accurately and easier registered by the digital processing of microphotographs [115]). Methods of the yeast detection of mitogenetic radiation were described in details in [4, 89].

It should be noted that there were about 20 negative experimental papers on mitogenetic effect, for example, [116-118]. Counter-criticism [22, 23] ascribed these failures to the serious deviations from the known methods [22, 23], their methodological errors were analyzed in the recent review as well [28]. Negative works made up less than $3 \%$ of the total number of experimental works on mitogenetic effect.

\section{Approaches to the registration of mitogenetic radiation}

For a rather long time after the discovery of the mitogenetic effect the biological detectors remained the only possible means of registration of UV-radiation of biological objects. Physical detectors of that time were not sensitive enough, and that made some authors to doubt the existence of this radiation itself, for instance [29]. In fact, biological detectors had a range of significant drawbacks. Firstly, such methods of detection were very time-consuming. For example, one 
registration of UV-radiation with onion detector required the counting of mitoses over microscopic fields of several thousands of cells. Secondly, experiments with biological detectors required very accurate operation and strict observation of procedures. Some authors failed to repeat the well-known experiments on mitogenetic effect due to the disregard of the methods of work with biological detectors (see details in Ref. [28]). Thirdly, variability of biological detectors themselves as well as variability of many environmental factors influencing their sensitivity made such method of registration of weak UV-radiation rather unstable. In fact, sometimes all the laboratories, which were wellexperienced in experiments on mitogenetic effect, observed an inexplicable failure of biological detectors. For instance, A.G. Gurwitsch reported that sometimes the yeast cultures successfully used in his laboratory completely lost their sensitivity for several days without apparent reason, moreover, all the researchers observed this phenomenon simultaneously in independent experiments. In a few days or even weeks their ability to detect radiation sometimes restored also without any apparent changes in the yeast culture. Similar simultaneous failures of all the bacterial detectors in some days were observed by L.K. Wolff and G. Ras [119]; they found that the detection was still possible, but required a longer exposure. O. Rahn, W. Heinemann, and W. Siebert headed the laboratories, where thousands of successful experiments with biological detectors were conducted, and they also reported about such cases. A.G. Gurwitsch suggested that these failures of biological detectors were related to external radiofrequency electromagnetic fields, L. Wolff and G. Ras explained them by specific changes of biological detectors themselves, there were a number of other suggestions like climatic changes etc. [3]. Besides that, some biological detectors demonstrated a clear seasonal sensitivity, for instance, an onion worked as a detector only since the end of September till April.

All these drawbacks of biological detectors and significant interest to the Gurwitsch's discovery induced active attempts to find physical and chemical methods of registration of mitogenetic radiation. W. Stempell suggested an approach based on the influence of UVradiation on the formation of Liesegang rings (concentric circles of precipitates that forms at slow diffusion of the drop of precipitant) [120] (as cited in Ref. [3]). This method seemed reliable for detection of UV-radiation from artificial sources, but the results for mitogenetic radiation from onion inducers were doubted, because of the influence of mustard oil evolved by onion on the Liesegang rings formation shown later [121]. The author took it into account in his further works [122, 123] (the last is as cited in Ref. [3]) and verified his first work (see Fig. 4). W. Stempell suggested one more detection method based on the accelerated decomposition of hydrogen peroxide under influence of mitogenetic radiation [124] (as cited in Ref. [3]). However, none of these methods was practiced widely, because of high sensitivity of
Liesegang rings formation and hydrogen peroxide decomposition to many different factors.

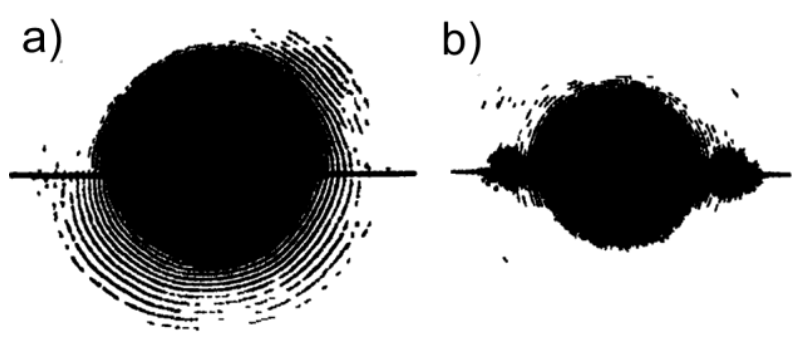

Fig. 4 Influence of mitogenetic radiation on Liesegang rings [123]. Onion pulp in metal tube with a slit (marked with a line) was used as a source of radiation. Liesegang rings were formed at precipitation of silver chromate in gelatine. a) exposure through cellophane, which is nontransparent for UV-radiation, b) exposure through a UV-transparent quartz plate (reprinted from Ref [3] with permission from E. Schweizerbart Science Publishers).

Later the method based on the flocculation of unstable colloidal solutions (sols of inorganic substances) was developed. Mitogenetic radiation accelerated the flocculation, the flocculation rate was characterized by a photoelectric differential turbidimeter $[125,126]$. This method was used only in a very few researches.

O. Rahn in his review [3] wrote that almost all the early researchers of the mitogenetic radiation had made unsuccessful attempts to register it with photographic plates. Sensitivity of such detectors was not enough even at 90-days' exposure to regularly renewed yeast culture [29]. Photoelectric elements of that time were also not enough sensitive for mitogenetic radiation detection [10].

The gas-discharge counters were the first physical detectors that reliably registered UVchemiluminescence of bioobjects. Various specially designed modifications of Geiger-Muller counters were used by B. Rajewsky [31-33], G. Frank and S. Rodionow [12, 13], W.W. Siebert and H. Seffert [34, 127], O. Glasser and H. Barth [35, 36], L. Grebe, A. Krost, L. Peukert [37] (as cited in Refs. [21, 23, 46]), R. Audubert [21] and others [3, 4, 23, 46]. The researchers registered radiation from working muscles, beating hearts, excited nerves, carcinomas, a wide range of redox reactions, "protein digestion" and many other biological inductors and chemical reactions. Besides that, no radiation was registered from the biological objects that earlier were found to be non-inductors of mitogenetic effect, for instance, muscles at rest. UVcomponent of radiation was demonstrated by comparison of measurement results for exposure through quartz and through glass or by introduction of monochromator between the inducer and the counter. Fig. 5 presents results for the sartorius muscle of the frog, which was stimulated electrically (special 
experiments verified that the muscle motion did not influence the measurement results) [13].

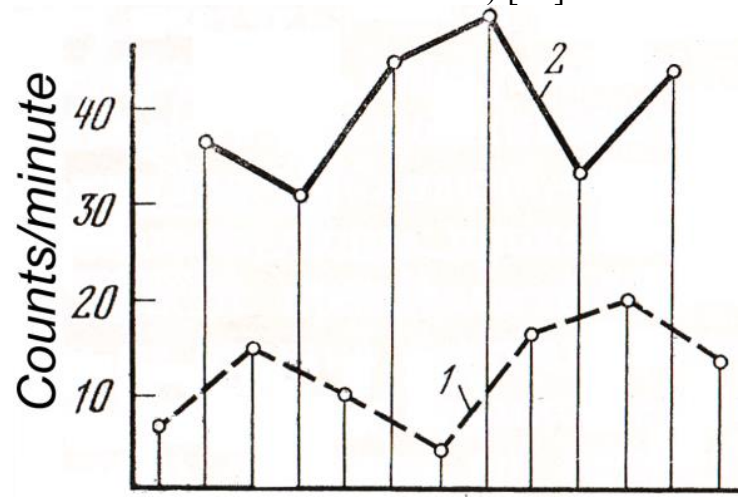

Fig. 5 Registration of mitogenetic radiation of the sartorius muscle of the frog, which was stimulated with electric current, with a gas-discharge counter: 1 - dark counts (resting muscle); 2 - signal counts (working muscle).

Gas-discharge counter registered radiation in intermittent periods of rest and work of the muscle (1 min. of rest, then $1 \mathrm{~min}$. of regular electric stimulation of the muscle: stimulation $1-2.5 \mathrm{sec}$ and pause 2-3 sec).

Reprinted from Ref. [13] with permission from John Wiley and Sons, Inc. (C) 1932 Federation of European Biochemical Societies.

Gas-discharge counters were rather imperfect devices for detection of such a weak radiation. Relative sensitivity of the counters made in one lot sometimes varied more than by an order of magnitude [36]. Registration of mitogenetic radiation required thorough selection of the best counters to get an acceptable signal/noise ratio. Besides that, it was necessary to test counters and replace them regularly because of desensitization.

In spite of all the drawbacks of these detectors and laboriousness of measurements the application of gasdischarge counters became an important step in the development of this field. In 1938 year at the conference of Faraday Society academician S.I. Vavilov summed up the results of these experiments as follows: «...emission of ultraviolet rays in many chemical reactions and biological processes is completely confirmed by usual physical methods. ...Wavelengths observed by Audubert belong to the same spectral range that was stated in Gurwitsch's laboratory...» [22].

Gas-discharge counters allowed researchers not only to prove an existence of mitogenetic radiation for a wide range of inductors, but also to estimate its intensity as 10-1000 photons $/ \mathrm{cm}^{2}$ sec. The upper estimate was indirectly corroborated by negative experiment with counters of lower sensitivity. Later the intensity range measured with gas-discharge counters was verified with photomultipliers [43-48, 128-130].

\section{Spectral analysis of mitogenetic radiation with biological detectors}

The first attempt to analyze the spectrum of mitogenetic radiation was not successful [8]. Onion pulp was taken as an inductor, onion roots served as detectors, between them the quartz spectrograph was placed. Obtained spectra was significantly different from the spectra measured later in other laboratories [3, 4]. A number of mistakes in the experimental method was stated in Ref. [4], however the basic experimental setup was successfully used later on (see, for instance, Fig. 6(a)).

The first trustworthy spectra were obtained by G.M. Frank [11]. Experimental setup was similar to the spectrograph of that time with a set of agar blocks with yeast culture instead of a photographic plate as a detector (Fig. 6(a)). One detector block corresponded to the band of wavelengths down to $50 \AA$. Frog's muscle stimulated electrically was used as a source of radiation (as an inductor of mitogenetic effect). Results of three experiments are shown in Fig. 6(b).
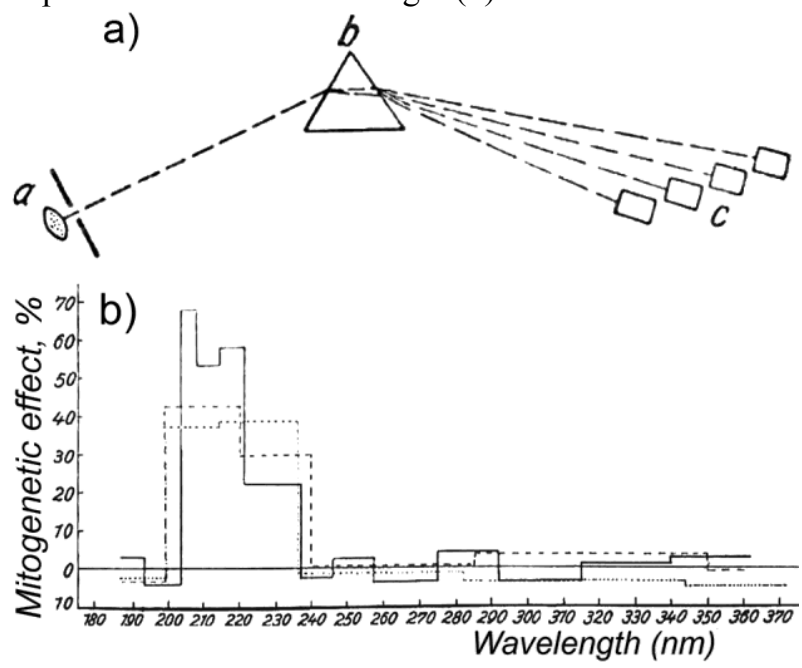

Fig. 6 Spectral analysis of mitogenetic radiation with biological detectors.

a) Experimental setup: (a) a sartorius muscle of the frog, (b) spectrograph (only a quartz prism and an optical slit are shown on the scheme), (c) agar blocks with yeast culture.

b) Three spectra of radiation from the electrically stimulated frog's sartorius. Mitogenetic effect is quantified as a change of budding index relative to the control yeast culture. Different step lengths correspond to the different width of yeast blocks.

Reprinted by permission from Springer Nature Customer Service Centre GmbH: Springer Nature Pflüger's Archiv für die gesamte Physiologie des Menschen und der Tiere "Die mitogenetische Strahlung des Muskels und ihre Verwertung zur Analyse der Muskelkontraktion,” G. Frank, M. Popoff (C 1930.

It was impossible to improve resolution significantly by the further miniaturization of yeast blocks. To get finer structure of spectra the bands of $10 \AA$ were isolated out with monochromator [131]. The setup with monochromator required significant time consumption, 
because the detectors had to be exposed one by one, usually not less than ten detectors per one band of wavelengths were exposed. Further improvements increased the spectral resolution up to $5 \AA$ [132].

Obviously, the spectral analysis of UV-radiation with biological detectors was limited by the very low intensities and rather narrow spectral range of sensitivity of biological detectors. The mitogenetic spectra indicated only presence or absence of radiation within discrete spectral bands without any information about its intensity, thus they were significantly different from usual spectra obtained with physical devices. At the same time biological detectors showed an unsurpassed sensitivity to the weak UV-radiation. The spectral analysis of weak UV-radiation became one of the first practical applications of mitogenetic effect. Similar installations with biological detectors allowed the finding and study of UV-chemiluminescence of a wide range of biochemical and chemical reactions. Fig. 7 presents mitogenetic spectra of a number of enzymatic reactions - splitting of phosphocreatine, glucose and other [73].

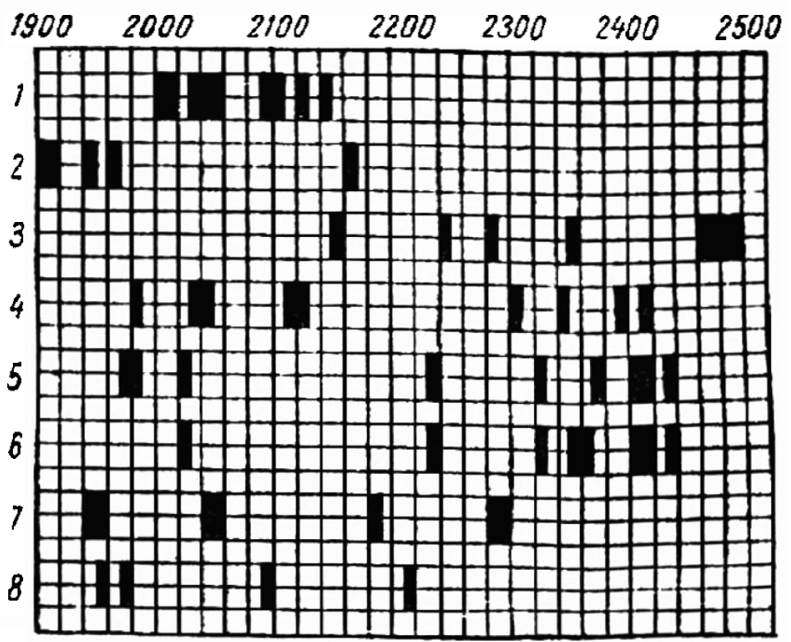

Fig. 7 Reference spectra of enzymatic cleavage reactions (reprinted with permission from Ref. [73]): 1 - phosphocreatine, 2 - glucose, 3 - nucleic acid and lecithin, 4 - peptides, 5 - maltose, 6 - sucrose, 7 - urea, 8 - lipids. The abscissa represents wavelengths in angstroms.

Comparison of the mitogenetic radiation spectra of various biological objects with the reference spectra of different biochemical processes allowed one to identify the processes causing mitogenetic radiation in any particular case. For instance, for long time A.G. Gurwitsch had been trying to explain unusual time dependence of mitogenetic radiation of the rabbit's eye during the starvation - it ceased completely and resumed after a week. The spectral mitogenetic analysis explained it easily: normal radiation was mainly due to glycolysis, which declines at starvation due to lack of glucose (after injections of glucose the "glycolytic" radiation restored very soon [73]), further starvation made proteolysis necessary for the life sustaining and the radiation had typical proteolytic spectrum in this period [87]. Mitogenetic spectral analysis of tumors demonstrated that alive surface cells of tumor with active metabolism had glycolytic and nucleolytic (related to the splitting of nucleic acid by phosphatase) spectra, while internal necrotizing tissues were the sources of radiation typical for proteolysis [133]. Mitogenetic spectra of the maltose cleavage and starch cleavage were identical and different from the spectra of the sucrose cleavage. A.G. Gurwitsch concluded from these results that starch had the bonds between hexoses of the same type as in maltose and different from the ones in sucrose, mitogenetic analysis data led to some other findings related to the structures of biochemical substances [4].

Mitogenetic spectral analysis was a research method that provided lots of scientific information ahead of the time (see, for instance, chapters "Mitogenetic analysis of cancer cell" and "Mitogenetic analysis of nerve excitement" in the book [73]).

Radiation spectra of various biological inductors were attributed to rather general types of processes (glycolysis, oxidation, phosphorilation, proteolysis etc.). It was not only due to the lack of knowledge about the biochemical reactions, much more it was due to the limited resolution of mitogenetic spectra, which allowed analysis of the most general spectral features. Researchers of mitogenetic spectra often mentioned that the bands of $1 \mathrm{~nm}$ very probably contained unresolved lines.

In the 1930-40s years the mitogenetic spectral analysis was a unique instrument for non-invasive noncontacting study of biochemical processes in living organisms. As A.G. Gurwitsch pointed out in the monograph [4] "in contrary to any biochemical methods, the analysis is made not after but during the functioning". This method was widely used for study of dynamic physiological processes: excitement of different nerves with various stimuli [134-136], muscle activity and other processes (see more about mitogenetic spectral analysis in monographs $[4,23,73$, 87]).

\section{Physical parameters and specifics of mitogenetic radiation of biological origin}

There are only the total intensity and the spectral range that were measured reliably enough among the parameters of mitogenetic radiation of bioobjects. Majority of biological inductors have spectral ranges within 190-260 nm [3, 4, 11, 134, 135, 137]. It should be noted, that there were no data on wavelengths below $190 \mathrm{~nm}$ because of the nontransparency of quartz used in prisms, cuvettes, windows of gas-discharge counters etc. Intensity of radiation varied within 101000 photons $/ \mathrm{cm}^{2} \mathrm{sec}$ depending on the inducer and its physiological state. For instance, the muscles of frogs just taken from natural reservoir radiated with much higher intensity than after several months in aquarium [13]. The mitogenetic effect induced by UV-radiation 
from artificial sources was studied in Refs. $[10,83]$. The dependences of the mitogenetic response of the biological detector from the wavelength and intensity of incident radiation were estimated in Ref. [10]. The authors used aluminium, zinc, cadmium sparks and mercury arc lamp as sources of radiation. The attenuating filters lowered the intensity by several orders of magnitude, after them the large double quartz monochromator isolated discrete spectral bands, and then the detector (yeast culture) was placed. Mitogenetic response was observed within the range of 206-265 nm. Its dependence on the intensity had a maximum with damping of the effect by «high» doses of radiation, while the range of intensities producing mitogenetic effect did not change greatly with the wavelength (Fig. 8).

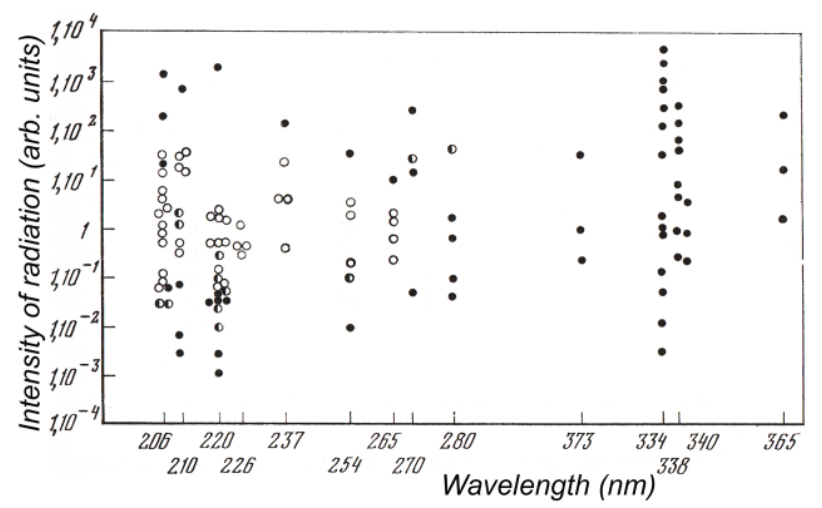

Fig. 8 Dependence of mitogenetic response of yeast detector on the intensity and wavelength of UVradiation from artificial sources (aluminium, zinc, cadmium sparks and mercury arc lamp). The unit of intensity corresponds to the photoelectric current of 5 $10^{-14} \mathrm{~A}$.

- - no mitogenetic response;

o- strong mitogenetic response;

D- weak mitogenetic response.

Reprinted by permission from Springer Nature Customer Service Centre GmbH: Springer Nature Naturwissenschaften "Über die Wellenlänge und Intensität mitogenetischer Strahlung," J. Chariton, G. Frank, and N. Kannegiesser (C) 1930.

Mitogenetic response of biodetectors required unexpectedly high intensity of artificial radiation [10]. First intensity estimations for natural mitogenetic radiation were published later $[12,13]$, however, by that time it had been known already that the radiation of bioobjects was so weak that it could be registered neither by photographic plates nor by usual photoelectric cells. Authors developed special highly-sensitive photoelectric installation, which detected $1 / 3$ of the threshold intensity of artificial radiation producing mitogenetic effect, but it was not enough for registration of natural mitogenetic radiation [10]. Thus, the same mitogenetic response of yeast detector required much higher intensities of the radiation from artificial source than from biological inductor. It manifested some specifics of UV-radiation of biological origin, which made biological detectors more sensitive to it than to the radiation from physical sources. Authors [10] related that to the high monochromaticity of the used physical sources and more complex spectra of biological inductors. They compared response of the yeast detector to the isolated spectral line $(210 \mathrm{~nm})$ and to an arbitrary set of spectral lines within the band of $205-215 \mathrm{~nm}$. Detector demonstrated much higher sensitivity to the less monochromatic radiation: the mitogenetic response was observed at the intensity levels one-two orders of magnitude lower (about $6-7 \cdot 10^{5}$ photons $/ \mathrm{cm}^{2} \mathrm{sec}$ ) (see Fig. 9) than for monochromatic radiation, however, still orders of magnitude higher than the intensity of biological inductors [10].

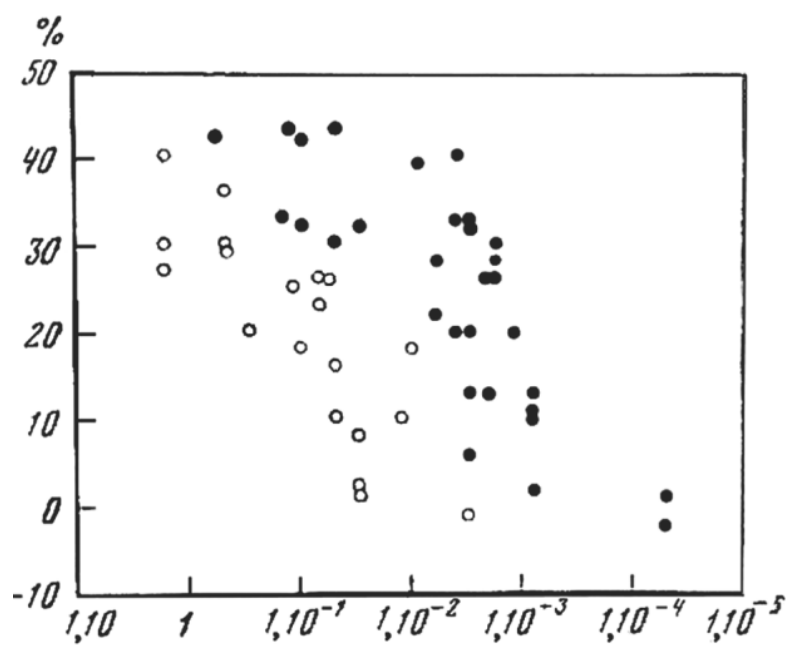

Fig. 9 Comparison of sensitivities of the yeast detector to the radiation of artificial UV-sources with higher and lower monochromaticities. Abscissa: intencities in relative units (the unit of intensity corresponds to the photoelectric current of $510^{-14} \mathrm{~A}$ ); ordinate: mitogenetic effect (\%).

- - radiation of higher monochromaticity (spectral line of spark discharge $210 \mathrm{~nm}$ ),

- - radiation of lower monochromaticity (arbitrary set of spectral lines within 205-215 nm).

Reprinted by permission from Springer Nature Customer Service Centre GmbH: Springer Nature Naturwissenschaften "Über die Wellenlänge und Intensität mitogenetischer Strahlung," J. Chariton, G. Frank, and N. Kannegiesser (C) 1930.

Researchers specially pointed out that they used a quite arbitrary set of spectral lines. They suggested that the threshold intensity probably could be lowered further if physical parameters of artificial radiation were similar to the ones of biological inductors. They mentioned that spectral composition, time dependence or other specific parameters may be of importance.

Higher sensitivity of biological detectors to the intermittent radiation was demonstrated earlier in experiments with yeast detectors and inductors [3, 4]. A rotating disk with one or more slits was placed between the detector and the inductor. Duration of exposure 
periods, their frequency and total time of exposure depended on the rotation frequency, the widths and locations of slits. It was shown that the intermittent radiation allowed one to get a mitogenetic response at the shorter exposure time/the lower intensity than for the continuous radiation. For instance, a stable mitogenetic response was obtained after just 12.5-13 seconds of intermittent radiation with the frequency of interruption of $100-800 \mathrm{~Hz}$, while it required 6-8 min of an exposure to continuous radiation. Thus, regular interruption lowered the duration of exposure in 30 times in comparison with continuous radiation. For continuous radiation the mitogenetic effect was observed at the inductor-detector distance of less than 3-4 cm, while regular interruptions of radiation increased the possible distance up to $15 \mathrm{~cm}$ (Refs. [4, 87]).

The experiments with slow approaching of yeast blocks also proved that the sensitivity of detector strongly depended on the time character of radiation influence. Yeast blocks were slowly moved from the distance, where the mitogenetic effect was not observed, to the distance, where the mitogenetic effect was stable in previous tests. Such a slow approaching corresponded to a gradual increase of the intensity of radiation. If the approaching was slow ( $>5-6$ minutes), the detector did not show any response to mitogenetic radiation; at the faster approaching ( $<3$ minutes) a stable mitogenetic effect was observed [4, 87].

Dependence of the sensitivity of biological detectors from polarization of radiation was also studied. Detectors were more sensitive to polarized radiation, i.e. mitogenetic effect was observed at the longer inductordetector distances [138]. Problems of polarization and time dependence of natural mitogenetic radiation were studied experimentally in several experimental works, but they did not give an unambiguous answer. It may be related to the high variability of these parameters for different biological inductors and their dependence from a number of factors.

Parameters of natural mitogenetic radiation and mechanisms of its biological detection were studied not enough to explain a higher sensitivity to the natural mitogenetic radiation. Maybe it is not a single parameter, but a set of parameters that make this radiation so specific for biological detectors.

\section{Blood radiation, cancer quencher and cancer diagnostics}

Mitogenetic radiation of blood was studied quite widely, because blood was an easily accessible and reliable inducer of mitogenetic effect and at the same time it was commonly used for medical diagnostics. It was demonstrated, that the blood of healthy humans, various mammals, birds and amphibians, as well as the hemolymph of crabs and molluscs radiated quite well. H. Gesenius wrote: "Healthy blood never fails. If a failure occurs, it is time to test either the yeast or the apparatus" [139]. It was shown, that the blood radiation in mammals was mainly related to glycolytic processes, whereas the blood of amphibians radiated due to oxidative processes [4, 24].

A detailed review of early studies of mitogenetic radiation of blood was presented in the second volume of the handbook of general hematology [140] (cited by Ref. [3]).

In various types of cancer diseases the blood radiation disappeared at the early stages of malignancy, long before the appearance of the first morphological signs of malignant growth, due to the UVchemiluminescence quenching by a highly specific substance. This substance was called a cancer quencher. In cancer diseases the radiation of blood [101], urine [102] and corneal epithelium [4] ceased completely. In contrast, malignant tumors themselves were extremely active sources of mitogenetic radiation [4, 84].

Physical and chemical properties of the quencher were studied in detail, although its chemical composition remained unidentified. The quencher was found in the albumen-free blood fraction, it had negative electric charge, in solution it was stable enough but thermolabile; quencher diffused through the collodion membrane only under electrophoresis conditions, withstood drying at room temperature, it could be adsorbed on kaolin and washed out with an alkaline solution [24]. Researchers concluded that the cancer quencher was "a peptide having a predominance of the enol form of peptide bonds", threadlike structure and length about $3 \mathrm{~nm}$ [24]. The works on the cancer quencher were the first ones that claimed a possibility to use a blood peptide as a tumor marker. It cannot be excluded that the cancer quencher was not a single peptide but a whole group of similar peptides (maybe even specific for different types of cancer) with the active sites quenching UV-chemiluminescence. Active part of the cancer quencher was rather small, after careful hydrolysis in hydrochloric acid this substance diffused though collodion membrane without loss of the quenching properties.

It should be noted that the mitogenetic radiation of blood ceased in some physiological states (physical [111] and mental [112] fatigue, starvation [4], senility [111]) and in various diseases (pernicious anemia, leukemia, pneumonia, sepsis $[87,110,140]$, chronic tonsillitis [141], diabetes, liver cirrhosis, etc. [4, 24]). It was found that in all cases not related to cancer diseases the blood radiation vanished due to the appearance of substances not quenching, but absorbing UV-radiation. These substances were called absorbers [24, 73]. Absorbers were found to be low molecular weight products of pathological metabolism, for instance, ketone bodies in diabetes. In contrast to absorbers the cancer quencher did not absorb UV-radiation significantly and did not change the UV-transmittance of thin layers of blood. Principal differences between the properties of the quencher and absorbers allowed to develop a method for the quencher detection in blood, which was based on the use of biological detectors of mitogenetic radiation. 
The quencher was found only in the blood of humans and animals with malignant tumors or in precancerous states leading to them. It appeared at the very early stages of malignancy. The blood radiation disappeared 9-12 days after the tumor inoculation to healthy rats, while the tumors could be palpated only 28-32 days after the inoculation [142]. In experiments on mice, the cancer quencher appeared in the blood on the 1st-2nd day after carcinoma implantation and disappeared within 3-8 days after radical surgery, longer absence of blood radiation always followed by tumor recurrences [143, 144]. Experiments on mice with regular skin application of carcinogens showed that the quencher appeared in the blood at the still reversible stages of carcinogenesis, when papillomas grew on the bald patches [24-26]. If the carcinogen applications were stopped after the cancer quencher appearance, tumors developed only in mice with persistent quencher, other mice demonstrated local hair recovery, disappearance of papillomas and quencher. The quencher was detected in the blood of mice since 32nd53rd day after the beginning of carcinogen applications and tumors were diagnosed only at day 191-222. Tumors were not formed in the mice, in which blood the quencher did not appear $[25,26]$.

Clinical studies of patients with different types of cancer demonstrated high accuracy of tumor diagnostics based on the cancer quencher (specificity and sensitivity $>95 \%$ ) and its successful application for the efficacy evaluation of implemented therapy [24-27, 73].

\section{Research from the middle 50s to present}

In the USA a general attitude to mitogenetic effect as a false phenomenon of "Soviet science" started forming as early as in the 30 s and works on this topic were quite rare [3, 75, 76, 145-148]. Then the "Iron Curtain" strengthened this public opinion. In Europe active research in this area ceased at the beginning of World War II, in the USSR it was victimized along with genetics after the famous session of the All-Union Academy of Agricultural Sciences in 1948. There was practically no research done in this area from 1948 till the middle $50 \mathrm{~s}$.

Invention of photomultipliers stimulated a new wave of interest in radiation of biological objects. Ultraweak photon emission of plants was first detected by L. Colli and U. Facchini in 1954 [149]. In the USSR scientific groups of B.N. Tarusov and Yu.A. Vladimirov selected the best samples of photomultipliers at producing factories, designed liquid nitrogen cooling systems and achieved an extremely high sensitivity [150-152]. With such devices, they managed to detect ultraweak photon emission from animal tissues, which was much weaker than from plants [38, 151-153]. As B.N. Tarusov was occasionally remembering later, they had been "leafing through the books of A.G. Gurwitsch and repeating all experiments one after another". Yet, the works of these authors were principally different from the original works on mitogenetic effect: the photomultipliers used by B.N. Tarusov et al. had much higher sensitivity to visible light than to UV light, moreover, the studied bioobjects were placed inside "absolutely dark chambers", which had to bring the mitogenetic UV-component of radiation to naught $[3,4]$, for more details see Ref. [28]. Thus, the radiation detected by these researchers had no relation to the mitogenetic effect.

At the same time the groups of A.A. Gurwitsch [43] and S.V. Konev [44], which continued studies with modified Geiger-Muller counters, started using photomultipliers as well. They demonstrated a reliable UV component in the ultraweak photon emission of yeast cultures and a number of different biological objects [154].

By the end of 60 s the ultraweak photon emission research had focused on the visible component, because its intensity was much higher than ultraviolet one. These works laid the foundation of the presently wellinvestigated area of ultraweak bio-chemiluminescence (now mostly called ultraweak photon emission) [38-42, 155-157]. In the following years the mechanisms of ultraweak photon emission in the visible-range were found out, namely free radical recombination accompanying oxidative processes in lipid phase of membranes [38], and the reaction cascades involved in these processes were described in details [40, 158, 159]. It was shown that some diseases led to the changes of such ultraweak photon emission of various tissues, blood, urine etc. [160, 161], and ultraweak photon emission can be useful for medical diagnostics, including cancer diagnostics [162, 163].

The principal difference between the visible and the UV-components of ultraweak photon emission was incapability of the former to influence mitoses, and thus its irrelevance to mitogenetic effect. Nevertheless, the researches on visible ultraweak photon emission were important for the mitogenetic effect area, not only because the photomultiplier technique was developed, and the possible use of ultraweak photon emission for medical diagnostics was demonstrated. Molecular mechanisms of ultraweak photon emission, well investigated in this period, confirmed the free-radical hypothesis of photon generation, initially proposed by A.G. Gurwitsch on the basis of his study of the mitogenetic effect.

In the middle $60 \mathrm{~s}$, when the visible ultraweak photon emission was rather well-studied phenomenon, the group of T.I. Quickenden started a series of experiments on mitogenetic radiation. Their first attempts to detect UV ultraweak photon emission from yeast and bacterial cultures were unsuccessful [164] and the authors hastened to claim the mitogenetic radiation as a disproved misconception of the "Soviet science". This work published in "Nature" well fitted in with the widespread opinion of those times about the "obscurantism" in the USSR, and had a significant negative influence on the general attitude to this field. Seven years later the authors significantly improved the experimental design (namely, they used a larger photomultiplier cathode, located the object closer to it, collected the askew radiation with mirrors etc.) and 
managed to detect definite and reproducible UV component of ultraweak photon emission from suspensions of yeast cells under conditions of oxygen saturation [165]. In the following 20-year-long series of works, the authors investigated ultraweak photon emission from different microbial cultures both in visible and UV ranges [47, 48, 128-130, 165-169]. They definitely confirmed the results on the intensity of UV ultraweak photon emission, its spectrum and stagespecificity (i.e. appearance at certain stages of the culture growth) obtained in the $1930 \mathrm{~s}-40 \mathrm{~s}$. This made the authors radically change their attitude toward the "early works" [166].

Two specific periods of photon emission were characteristic for growth of all investigated cultures: a small reproducible peak of ultraweak photon emission in the period of active growth (exponential and linear growth phase) and much more intensive, but highly variable radiation in the stationary phase (Fig. 10).

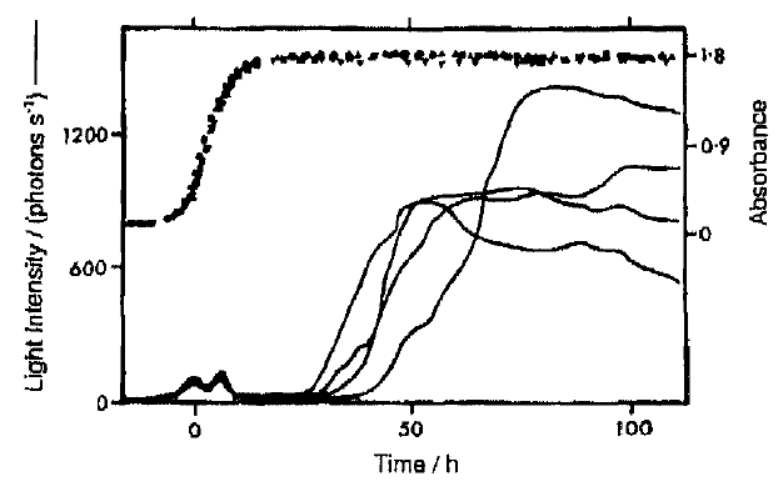

Fig. 10 Luminescence of Candida utilis (solid lines) and their growth dynamics (dots). 0 time point - time of half-maximal culture density. Reprinted from Ref. [48] with permission from John Wiley and Sons, Inc. (C) 1992 by John Wiley \& Sons, Ltd.

During the period of active growth the ultraweak photon emission showed a definite UV component, 20$40 \%$ of total intensity of ultraweak photon emission, which was $10-100$ photons $/ \mathrm{cm}^{2} \mathrm{sec}$ (Fig. 11). The stationary-phase ultraweak photon emission had only visible component. The visible ultraweak photon emission (in both periods) corresponded to lipid peroxidation processes, increasing in respiratorydeficient cultures due to the lack of "physiological ways of oxygen utilization" $[47,48,130]$. The UV component was shown to be: (1) not connected to lipid peroxidation; (2) not cosmic-rays excited fluorescence; (3) oxygen-dependent; (4) not connected to a number of key biochemical processes [48].

The authors pointed out that UV component appeared at the same stages of growth as mitogenetic radiation, had the similar intensity, wavelength and other characteristics, and also suggested "oxidative side reactions associated with protein synthesis" as its possible source [48].

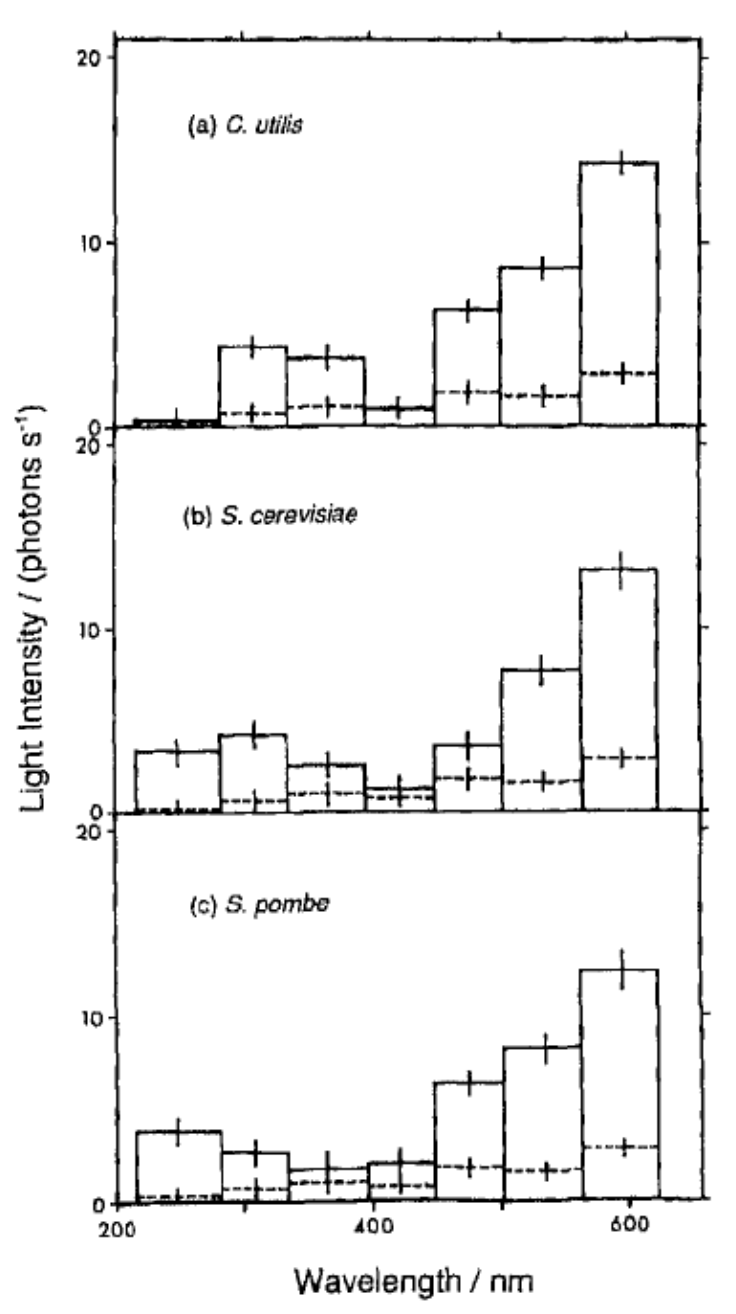

Fig. 11 Ultraweak photon emission spectra of various species in the linear-growth phase: (a) C. utilis, (b) S. Cerevisiae, (c) S. pombe $(50 \%$ confidence intervals). The growth medium emission spectra are shown with dashed lines. Reprinted from Ref. [48] with permission from John Wiley and Sons, Inc. (C) 1992 by John Wiley \& Sons, Ltd.

Yet these authors failed to observe the main (biological) mitogenetic effect $[167,170]$. They thoroughly reproduced the conditions necessary for the culture-inducer to radiate, but violated a number of critically important requirements to the culture-detector, e.g. the recipient culture was in stationary (G0) phase, though stationary-phase cultures had been shown in earlier works to be absolutely insensitive to mitogenetic radiation $[3,4,77,78]$ (see analysis of other mistakes in [28]).

Another wave of interest to the problem of mitogenetic effect and distant biological interactions aroused in the $1980 \mathrm{~s}-90 \mathrm{~s}$ due to the activity of the International institute of biophysics in Germany, which was organized and headed by F.-A. Popp. It united research groups of 19 institutes from 13 countries in an international network, including a number of scientists from Russia (V.L. Voeikov, A.B. Burlakov, L.V.Beloussov and their groups), Israel 
(M.A. Lipkind), the Netherlands (R. and E. van Wijks), Italy (F. Musumeci, H. Niggli), China (J.J. Chang), India (R. Bajpai), etc. The scientific discussion of that time was mainly devoted to F.-A. Popp's beautiful hypothesis of specific quantum properties of biological ultraweak photon emission: abnormally high coherence, the so-called squeezed-state, etc. [171-174]. The researchers measured not as much spontaneous ultraweak photon emission of biological objects, as their photo-induced delayed luminescence. Based on different parameters of its dynamics, they calculated "degree of coherence" of the "inner electro-magnetic field of the object" [172]. Yet, none of their hypotheses has got an experimental proof by this time [42, 50, 51], while a huge number of popular "sensational" articles greatly compromised the whole research area.

Simultaneously, using both their own equipment and the (quite powerful) instrumentation of the International institute of biophysics, a number of authors were analyzing dynamics of spontaneous ultraweak photon emission from different biological objects: oocytes and embryos of fish, frogs $[175,176]$, cell and microbial cultures [63, 177], chicken eggs [54], human blood $[178,179]$ and simple aqueous systems [180]. The authors were searching for specific temporal order in ultraweak photon emission, which would be more likely to "suspect" in mitogenetic component than in the visible one. For this purpose they applied methods of digital processing of noisy signals (autocorrelation, Fourier analysis, wavelet, multifractal analysis, etc.) to the raw data from photomultipliers. Sometimes the authors claimed interesting regularities in ultraweak photon emission, however, they failed to show any parameters that would confidently and repeatedly distinguish the ultraweak photon emission of biological objects from corresponding controls. Wideband photomultipliers $(\sim 200-800 \mathrm{~nm})$ with maximal sensitivity in the visible light were used in practically all these works, and (consequently) the objects were placed in very dark chambers, where mitogenetic effect could not be observed according to the "early works". Thus, as far as mitogenetic radiation was concerned, these attempts were practically hopeless.

The works on mitogenetic effect also stimulated investigations of possible distant (optical) interaction between microbial cultures [66, 68, 177, 181], cell cultures [60-62, 182-185], oocytes and embryos of fish $[61,62]$ and frogs [186]. Yet, none of the groups managed to obtain regularly reproducible results, that could be considered a solid proof of the phenomenon $[57,68,70,187]$. It should be noted that all (!) these works on mitogenetic effect suffered from technical mistakes and did not stand up to scrutiny. All of these authors seem to have made their experiments without due technical equipment, financial support and scrupulousness, which (together with "delicacy" and methodical difficulty of observing the phenomenon [28], led to the low level of evidence in these works. The authors didn't try to reproduce the known results under previously established conditions and follow the detailed methodical recommendations from "early works", but rather made attempts to get analogous results under conditions never investigated before (or even previously proven ineffective).

The problem of possible mechanisms of generation and detection of "mitogenetic signals" has been actively discussed since A.G. Gurwitsch's times up to these days [3, 4, 28, 50, 51, 69, 188]. The mechanisms of emission of UV photons are still unknown. It should be mentioned, that UV luminescence accompanying a number of branching-chain reactions (e.g. hydrogen peroxide + glycine) was studied in more details with photomultipliers and some specific features of these processes were found [43, 189, 190].

All basic works on cancer quencher were published only in Russian [24-27, 144, 191, 192] and remained almost unknown abroad. There were very few significant investigations related to quencher after the 1940 s, and practically all of them were made in the group of A.A. Gurwitsch. The dissertation of L.I. Sneshko [193] on the role of spleen in the cancer quencher emergence described one of the most interesting findings of this period. If the spleen had been extirpated several days before the cancer induction, the cancer quencher was not secreted into blood during the following carcinogenesis, and mitogenetic radiation of blood did not change as well. V.F. Eremeev investigated appearance of cancer quencher in liver of mice with implanted malignant tumors [55]. One of the chapters of the book [23] was devoted to the mitogenetic analysis of cancer cell biology and works on cancer quencher.

\section{Conclusion}

The review covers researches on the mitogenetic radiation made in 1923-1948 years.

Main achievements of this period:

- the mitogenetic effect was discovered;

- this effect was attributed to ultraweak UVradiation, its spectral range and intensity were estimated;

- the mitogenetic effect was shown to be species-nonspecific;

- UV-chemiluminescence of a number of biochemical and chemical reactions was found out and their spectra were analyzed with use of biological detectors;

- mitogenetic radiation of various biological objects was attributed to the well-known biochemical processes;

- a highly-specific universal tumor marker, so called cancer quencher, was found in blood; it was shown to be a peptide (or group of similar peptides) quenching UV-chemiluminescence of blood.

Some valuable results had been proved later. Measurements with photomultipliers corroborated an existence of UV-chemiluminescence of bio-objects, its intensity and spectral range evaluations. Gurwitsch's hypothesis of photon generation in branching-chain reactions with recombination of free radicals was shown 
to be correct for chemiluminescence in the visible region. Possibility to use a blood peptide as a highlyspecific tumor marker was proclaimed 30 years before the alpha-fetoprotein and this statement was revolutionary for the 1930s. This conclusion was made exclusively on the basis of experiments with mitogenetic radiation of blood. An amazing correlation of the results of this cancer diagnostics for newlyadmitted patients with their final diagnoses (specificity and sensitivity $>95 \%$ ) hardly could be explained by mere coincidence [24-27].

We do not claim all the results on mitogenetic radiation as postulates, however, there is no reason to consider them as falsification, mass misconception, or common systematic errors. These experiments were conducted in the leading laboratories of the world by distinguished scientists and their groups. All the main experiments had passed multiple verifications in different reputable laboratories. Negative works made up less than $3 \%$ of the total number of publications on mitogenetic effect; all of them had been refuted in response criticism with clear statement of errors. Before the World War II all the results on the subject were widely discussed at international level, supporting experimental data were quite massive, many publications included thorough descriptions of experimental methods and detailed protocols and they deserve serious attention. After the end of the 40s the attempts to reproduce the experiments on mitogenetic radiation were rather scarce. As far as we know, no significant researches on mitogenetic radiation were published in the last years. Recently, there were a number of papers devoted to the distant interaction of biological objects (for example, Ref. [67]), where the authors mentioned that maybe the observed effects were related to the mitogenetic radiation. However, they did not present any proof that the radiation underlying the effects belonged to UV range or stimulated mitoses. We strongly doubt that these effects related to mitogenetic radiation because of too long distance of interaction and some other reasons. In other works (for instance, Ref. [185]) the experimental conditions made the nature and the reproducibility of the effect doubtful, and they can not be attributed to the mitogenetic effect as well. We consider all these works irrelevant to the subject of this review.

The experimental verification of the results on mitogenetic radiation at the up-to-date level is possible and necessary in relation with basic science (for instance, for the clarification of possible role of UVchemiluminescence in regulatory processes in cells and multicellular organisms) and practical applications (prospects of an effective early-stage cancer diagnostics, optimization of biological processes with "mitogenetic factors" in R\&D and industries).

Resumption of research on cancer quencher is especially important from the practical point of view: the identification of this peptide (or group of similar peptides), the finding of its role in carcinogenesis, verification of the described methods of the quencher extraction from blood and applicability of quencher detection to early screening of cancer, control of efficacy of implemented surgery/therapy, and timely detection of metastases. The most popular argument against the cancer quencher existence is the following one. If the experimental results on cancer quencher were true, then it would be widely used by now. At the same time the history of science demonstrates quite a few cases when true hypotheses and experiments were verified after decades and even centuries of oblivion. All the key experimental works on the cancer quencher were published in Russian [24-27, 144, 191-193] and remained almost unknown to the English readership, while in the USSR this scientific direction did not recover after the persecution in 1948 year.

Up-to-date methods of cytogenetic, cellular and biomolecular analysis, controlled environments, accurate control of biological states of inductors and detectors, spectroscopy, complex experimental design techniques and statistical tools allow to develop clear proofs or disproofs of early results on mitogenetic radiation. Verification of these results requires a thorough study of used experimental designs and methods with special attention to the details, which were examined in some "old works" [3, 4, 23, 145, 146, 194] and newly analyzed recently [28].

Substantial progress in biomolecular analysis, cell biology and biochemistry, physical methods and experimental techniques let us expect these undeservedly forgotten researches to be resumed at the up-to-date level.

This review is mainly grounded on the publications from the unique archive of scientific literature collected by A.G. Gurwitsch, his wife L.D. Gurwitsch, their daughter A.A. Gurwitsch and grandson L.V. Beloussov.

\section{Disclosures}

All authors declare no conflict of interests for this manuscript and have no a financial interest in the materials used in the manuscript. 